\title{
Industry Learning Environments and the Heterogeneity of Firm Performance*
}

\author{
Revised April 2008
}

\begin{tabular}{|c|c|}
\hline Natarajan Balasubramanian & Marvin B Lieberman \\
\hline College of Business Administration & UCLA Anderson School of Management \\
\hline Florida International University & 110 Westwood Plaza, B415 \\
\hline $11200 \mathrm{SW} 8^{\text {th }} \mathrm{RB} 346$ & Los Angeles, CA 90095-1481 \\
\hline Tel: (305) 348-3300 & Tel: (310) 206-7765 \\
\hline Email: balasubn@fiu.edu & Email: marvin.lieberman@anderson.ucla.edu \\
\hline
\end{tabular}

*DISCLAIMER: The research in this paper was conducted while the authors were Census Bureau research associates at the California Census Research Data Center (CCRDC). Research results and conclusions expressed are those of the authors and do not necessarily indicate concurrence by the Bureau of the Census. The results presented in this paper have been screened to ensure that no confidential data are revealed.

\section{ACKNOWLEDGEMENTS}

We thank an anonymous referee for insightful comments that helped us significantly improve our paper. We thank Becky Acosta at the CCRDC for her help with the project proposal and prompt processing of our disclosure requests. We have benefited immensely from insightful comments by Emin Dinlersoz, Susan Cohen, participants at the CRES-Gort and ACAC conferences and the 2006 AOM annual meeting. Natarajan Balasubramanian thanks Jagadeesh Sivadasan for numerous discussions on this study, Dan Ackerberg, Roberto Alvarez, Michael Darby, Hugo Hopenhayn, Raphael Lam, Jeongsik Lee, Gabriel Natividad and Mariko Sakakibara for their constructive comments and Hyowook Chiang, John Haltiwanger and Ron Jarmin for kindly sharing various data. The CCRDC generously provided support to Natarajan Balasubramanian and covered the data access fees. 


\begin{abstract}
This paper characterizes inter-industry heterogeneity in rates of learning-by-doing and examines how industry learning rates are connected with firm performance. Using data from the US manufacturing sector, we measure the industry learning rate as the coefficient on cumulative output in a production function. We find that learning rates vary considerably among industries and are higher in industries with greater $\mathrm{R} \& \mathrm{D}$, advertising, and capital intensity. More importantly, we find that higher rates of learning are associated with wider dispersion of Tobin's $q$ and profitability among firms in the industry. These findings suggest that learning intensity represents an important characteristic of the industry environment that affects the range of firm performance.
\end{abstract}

Keywords: Learning, Firm Heterogeneity, RBV, Productivity 


\section{INTRODUCTION}

This paper examines a key aspect of the firm's industry environment - the importance of learning from direct operating experience or "learning-by-doing" in determining business performance. Industries vary considerably in the relevance of learning-by-doing to firm performance. In some industries, products and processes may be relatively simple, or entrepreneurs and managers may be able to leverage external sources (e.g. specialized technology suppliers, consultants or competitors' employees) to acquire knowledge about their business operations. Other industry environments may not support such acquisition of knowledge or may involve complex, knowledge-intensive processes and products, thereby constraining firms to improve performance largely through direct experience. In such environments, learning-by-doing may significantly affect firm performance. In this study, we focus on the importance of accumulated experience in the production process as a measure of the importance of learning-by-doing in an industry ("industry learning intensity"). Further, we examine how differences in industry learning intensity are associated with business performance. Using plant-level data from the US Census Bureau on over 55,000 manufacturing plants from 1973 to 2000, we estimate the industry learning rate as the coefficient on prior cumulative output in a production function. Applying these industry learning rates to firm data from Compustat, we find that the cross-sectional variation in business performance within an industry, as measured by the inter-percentile range (10th to 90th) of firm $q$ and firm profitability, is much greater in industries with higher learning intensity. Such findings suggest that learning intensity is an important characteristic of the industry environment that has been omitted from prior studies of firm and industry performance.

This study draws from a long line of literature on organizational learning and "learning 
curves", which have been studied since the 1930s. The "learning curve" or the empirical relationship between unit cost of production and operating experience has been estimated for numerous industries - e.g. ships (Rapping, 1965; Thornton and Thompson, 2001), chemicals (Lieberman, 1984) and semiconductors (Gruber, 1994 and Gruber, 2000) - and generally appear to follow a "power-law" i.e. the unit cost of production decreases at a decreasing rate with increasing experience, typically measured as prior cumulative output While most studies have found that performance improves as organizations accumulate operating experience, the rate of learning appears to vary across industries. In a review of 22 field studies on learning-by-doing, Dutton and Thomas (1984) found that "progress ratios" (i.e. the percentage decrease in unit costs with a doubling of cumulative experience) ranged from $55 \%$ to over $100 \%$. Learning rates have been found to vary within an industry and even within subunits of the same firm. Hayes and Clark (1986) examined productivity in factories and found that learning curves varied significantly across factories within the same company. In an analysis of cardiac surgery departments implementing a new technology for minimally invasive cardiac surgery, Pisano, Bohmer and Edmondson (2001) found that the learning curve slope varied significantly across organizations. While these studies have demonstrated that learning rates vary significantly among organizations and industries, these studies have drawn from limited data sets and have not attempted to characterize differences in learning rates across a broad range of industries.

This study also links to another line of papers, mostly in the Structure-ConductPerformance literature that examines how industry factors affect firm performance. Many empirical studies have examined how the variables such as industry structure, R\&D intensity and advertising intensity affect firm performance (See Schmalensee (1989) for a review.). The industry learning intensity or the role of direct experience has not been studied (empirically) as a 
variable that could affect firm performance. This is a bit surprising given that a number of studies have argued that the learning curve has implications for competitive strategy and may be used to generate "first-mover advantages" (e.g. Spence, 1981; Lieberman, 1987).

This study makes two contributions to the existing literature on learning. First, it provides a broad-brush characterization of plant-level learning-by-doing in over 100 SIC-3 digit industries in the US manufacturing sector. This characterization reinforces findings in prior studies that industries vary considerably in their learning rates. In addition, it provides reasonably comparable quantitative estimates of the importance of learning from direct experience across industries. Most prior studies have focused on a single product or service, largely due to non-availability of longitudinal data across industries. In this study, we use a large sample drawn from US Census Bureau data that span the entire US manufacturing sector. We adopt a production function approach and measure the industry learning intensity as the coefficient on prior cumulative output in a production function. This approach is approximately equivalent to the traditional unit-cost learning curve and provides a reasonably uniform measure of learning rates across industries, albeit subject to some limitations. We find that the industry learning rate displays considerable heterogeneity across industries and that it is positively correlated with industry capital-labor ratio, R\&D intensity and advertising intensity, even after controlling for joint industry-year fixed effects or plant fixed effects. These correlations are consistent with the intuitive notion that learning-by-doing may be more important in industries with greater complexity.

More importantly, our study demonstrates that industry learning intensity has robust relationships with firm performance. In particular, we find that the cross-sectional heterogeneity of firm performance within an industry, as measured by the inter-percentile range of firm profits 
or firm $q$, is higher in industries with higher rates of learning. In other words, in such industries, the difference between the "best" and the "worst" (conditional on survival) firms is considerably higher. Taken together, our findings add to the existing literature by introducing industry learning intensity as an important component of the industry environment that may explain competitive heterogeneity.

\section{LEARNING-BY-DOING}

Learning-by-doing is generally considered to be the result of organizational search for better routines combined with trial and error experimentation, though it has been modeled in a number of different ways (Levitt and March, 1988; Muth, 1986; Jovanovic and Nyarko, 1995). In this paper, we use the information-theoretic model developed by Jovanovic and Nyarko (1995) to develop hypotheses that characterize inter-industry variations in the rate of learning

and relate the rate of learning by doing to heterogeneity of firm performance. ${ }^{1}$ One advantage of this model is that it relates characteristics of the underlying learning processes to the learning rate. Another advantage is that the model allows us to examine the impact of changes in the learning rate on the heterogeneity of firm performance.

Here, we summarize the model briefly. (Technical details can be found in the Jovanovic and Nyarko paper.) Decision-makers (e.g., managers, engineers, workers) make decisions that affect the efficiency of a production activity. The efficiency is determined by how far the production decisions are from their "ideal" values. More specifically, the efficiency $q$ is defined as:

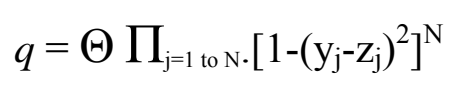

\footnotetext{
${ }^{1}$ We thank an anonymous referee for pointing us in this direction.
} 
where $\mathrm{N}$ is the number of tasks that activity requires, $\mathrm{z}_{\mathrm{j}}$ is the decision for the $\mathrm{j}^{\text {th }}$ task, and $\mathrm{y}_{\mathrm{j}}$ is the "ideal" for the $\mathrm{j}^{\text {th }}$ task. ${ }^{2}$ Note that efficiency is maximized at $\mathrm{z}=\mathrm{y}$, and the maximal level of efficiency is $\Theta$. The ideal level ' $y$ ' is a random variable that the decision-makers do not have complete information about, prior to production. Specifically,

$$
\mathrm{y}=\theta+\mathrm{w}
$$

where $\theta$ represents the optimal way (on average) to perform the activity, and w represents transitory disturbances that have zero mean and variance $\sigma^{2}{ }_{\mathrm{w}}$. Decision-makers know the variance of $\theta, \sigma_{\theta}^{2}$, but do not know its mean. Upon completing a production run, decision-makers use information learnt from the outcome of that production run to revise their estimates of the mean of $\theta$. As the number of production runs increases, decision-makers have increasingly precise estimates of the mean of $\theta$ but they never know it exactly because of the presence of disturbances.

This formulation, though simple, has three distinct dimensions of complexity. The first, $\mathrm{N}$, is the most intuitive. The greater the number of tasks that any production activity requires, the greater the number of decisions involved, and hence, higher the complexity of the activity. However, it is not necessary that all activities that have a high number of tasks be equally complex. It is possible that even though the number of tasks involved is very high, the decisionmakers have a lot of information about the tasks involved, and hence, the uncertainty surrounding the optimal decision is small. The variance of $\theta, \sigma_{\theta}^{2}$, is the second dimension, and captures the uncertainty about the optimal way to perform a specific task. Interpreted this way, tasks that are relatively new to industry participants are likely to have a greater variance. The

\footnotetext{
${ }^{2}$ The implications do not depend on the choice of this particular functional form. Jovanovic and Nyarko(1995) show that the findings from their model are robust to different functional forms. However, they do not explore interaction effects (Levinthal, 1997), which may add levels of complexity beyond the dimensions considered here.
} 
third distinct dimension is the importance of transitory disturbances w (as measured by the variance, $\sigma^{2}{ }_{w}$ ). In situations with low levels of such disturbances, decision-makers can glean more useful information from each production run than they can in contexts where these disturbances are high.

These dimensions of complexity capture important elements of the learning environment in manufacturing plants, which are likely to vary greatly across industries. For example, one would expect complexity along all three dimensions to be low in very mature industries such as leather goods and yarn production, where technology is well-understood and the production process consists of a small number of stages that can be readily observed. At the other extreme, complexity is likely to be high in industries such as computer manufacturing and petroleum refining, which incorporate a large number of production steps. Given the rapid pace of change in computer technology, knowledge of optimal methods from previous product generations provides only limited guidance for current practice, so uncertainty is high. In the case of petroleum refining, work-in-process can be monitored only indirectly, and variations in the quality of crude oil make it hard to identify the optimal process in any given plant. Although comparative industry data are not available, at a broad level one can conceive of the complexity of manufacturing plants as an increasing function of the number of process stages $(\mathrm{N})$, and the degree of uncertainty $\left(\sigma^{2}{ }_{\theta}\right)$ and "noise" $\left(\sigma^{2}{ }_{\mathrm{w}}\right)$ arising at each stage.

Based on this formulation, Jovanovic and Nyarko (1995) derive a formula for the expected efficiency on production run $\tau$.

$$
\mathrm{E}_{\tau}\left(\mathrm{q}_{\tau}\right)=\Theta\left(1-\mathrm{x}_{\tau}-\sigma^{2}{ }_{\mathrm{w}}\right)^{\mathrm{N}}
$$


where $\mathrm{x}_{\tau}=\sigma^{2}{ }_{\mathrm{w}} \sigma^{2}{ }_{\theta} /\left(\sigma^{2}{ }_{\mathrm{w}}+\tau \cdot \sigma^{2}{ }_{\theta}\right)$. Noting that $\mathrm{x}_{\tau}=0$ as the number of production runs tends to infinity, we can define the eventual expected efficiency as

$$
E\left(q^{*}\right)=\Theta\left(1-\sigma^{2}\right)^{N}
$$

Dividing equation 3 by equation 4, we obtain a learning curve that is a function of the three dimensions of complexity.

$$
\rho=\left(1-\mathbf{x}_{\tau}-\sigma^{2}{ }_{w}\right)^{\mathrm{N}} /\left(1-\sigma^{2}{ }_{\mathrm{w}}\right)^{\mathrm{N}}
$$

Insert Figure 1 about here

In figure 1, we plot logarithm of this learning curve for different values of the parameters. It is evident as complexity increases, as measured by any of the three dimensions, the slope of the learning curve increases. The reason for this increase in the slope of the learning is that in more complex situations, decision-makers start at a lower level of efficiency, and take longer to reach the potential maximum. This leads to our first hypothesis.

Hypothesis 1: The rate of learning by doing will be higher in industries with greater complexity.

The model also provides a testable hypothesis regarding the relationship between industry learning intensity and heterogeneity of performance. Jovanovic and Nyarko (1995) define the heterogeneity of performance in terms of the squared coefficient of variation of efficiency (i.e. the variance divided by the square of the mean), $v\left(\mathrm{q}_{\tau}\right)$, and derive an expression for this measure of heterogeneity.

$$
v\left(q_{\tau}\right)=\left[1+\operatorname{Var}\left(q_{\tau}\right) /\left[E_{\tau}\left(q_{\tau}\right)\right]^{2}\right]^{N-1}-1
$$


where $\operatorname{Var}\left(\mathrm{q}_{\tau}\right)=2 . \sigma_{\mathrm{w}}^{4}\left[1+\tau \cdot \sigma_{\theta}^{2} /\left(\sigma^{2}{ }_{\mathrm{w}}+\tau \cdot \sigma_{\theta}^{2}\right)^{2}\right]$ and $\mathrm{E}_{\tau}\left(\mathrm{q}_{\tau}\right)$ is as in Equation (3)

Figure 2 plots the logarithm of the measure of heterogeneity in Equation (6) versus the logarithm of the cumulated number of production runs. The relative inequality for any cohort of firms is high initially and then eventually decreases to an asymptotic level. Also, as observed by Jovanovic and Nyarko (1995), for some parameter values, the relative inequality increases initially before it starts decreasing. The intuition behind this pattern is that even though the decision-makers may all start with the same level of experience, some may receive more favorable signals than others-either due to luck or ability - which generates inequality among the decision-makers. As time progresses, the impact of this difference decreases though it never becomes zero because of the presence of transitory disturbances. More interestingly, the heterogeneity is positively associated with complexity. Irrespective of the dimension of complexity, figure 2 shows that as complexity increases, the heterogeneity of observed efficiencies increase. The intuition is the same as before - the difference in the quality of signals received by the decision-makers leads to differences in the observed efficiencies. As complexity increases, the variance of the signals increases, thereby increasing the observed heterogeneity in efficiency.

Insert Figure 2 about here

This leads us to our second hypothesis.

Hypothesis 2: The heterogeneity of firm performance will be higher industries with higher rates of learning. 


\section{MEASURING INTENSITY OF LEARNING-BY-DOING}

The traditional approach to measuring learning-by-doing for a product is to estimate a power-law function of the following form:

$$
\mathrm{C}=\mathrm{AX}^{-\lambda}
$$

Where:

$\mathrm{C}$ is the unit cost of the product;

A is a constant;

$\mathrm{X}$ is a measure of experience, typically prior cumulative production; and $\lambda>0$ is the rate of learning-by-doing.

This formulation is purely empirical and is a reduced form representation of the various processes of learning from direct experience. The disadvantage of this approach is that it requires detailed cost and production quantity data, which are not easily available for a large number of firms. Our method for measuring learning-by-doing follows Bahk and Gort (1993) and is a variant of the traditional approach. Bahk and Gort (1993) incorporate learning-by-doing within a production function and estimate the coefficients using data from individual manufacturing plants. Following their approach, we can write:

$$
\mathrm{Y}_{\mathrm{ijt}}=\Phi_{\mathrm{jt}}\left(\mathrm{K}_{\mathrm{ijt}}\right)^{\alpha}{ }_{\mathrm{j}}\left(\mathrm{L}_{\mathrm{ijt}}\right)_{\mathrm{j}}^{\beta}\left(\mathrm{X}_{\mathrm{ijt}}\right)^{\lambda} \mathrm{v}_{\mathrm{ijt}}
$$

Where

$\mathrm{Y}$ is the current period real value added, measured as real revenues less real materials expenses;

$\Phi$ is a constant (explained below);

$\mathrm{K}$ and $\mathrm{L}$ are real capital stock and quantity of labor, respectively; 
$\mathrm{X}$ is prior cumulative output, a measure of experience;

$\alpha, \beta$ and $\lambda$ are all positive and less than 1

$v$ is a plant-specific term (explained below);

and subscripts $i, j$ and $t$ refer to plant ' $i$ ', industry ' $j$ ' and year ' $t$ ' respectively.

This formulation is an extension of the widely used Cobb-Douglas production function. In addition to the usual inputs of capital and labor, prior operating experience is considered an "input" into the production process in the sense that a higher level of operating experience increases output for any given level of capital and labor. Hence, $\lambda$, the coefficient on prior experience denotes the industry learning intensity.

We can interpret the learning coefficients obtained from this approach in two ways. First, the coefficient $\lambda$ can be interpreted in a straightforward manner as the importance of learning (from direct experience) in the production process. A higher value of $\lambda$ implies a greater role for accumulated experience in the production process. We could also interpret learning to be an improvement in "productivity" resulting from experience. Productivity (or more precisely, Total Factor Productivity) as defined in the economics literature is a measure of the efficiency of physical resource use. Hence, firms with higher productivity have the capability to generate more or better quality output using the same amount of physical resources. There are two physical resources considered above, capital and labor. So, we could define productivity of a plant as $\mathrm{P}_{\mathrm{ijt}}=\Phi_{\mathrm{jt}}\left(\mathrm{X}_{\mathrm{ijt}}\right)^{\lambda} v_{\mathrm{ijt}}$, which is simply the right hand side of Equation 8 excluding the inputs of physical resources. The second term of this expression, $\mathrm{X}_{\mathrm{ijt}}{ }^{\lambda}$, is the increase in productivity resulting from accumulated direct operating experience and reflects learning-by-doing. The coefficient $\lambda$ here is a measure of the importance of direct experience in productivity improvement. This definition also enables us to isolate learning-by-doing from other sources of 
productivity improvement. The first term, $\Phi_{\mathrm{jt}}$, captures any industry-wide improvements in productivity (subscript 'j' refers to industry). This may occur, for instance, because of innovations in the equipment used in the industry, or because of improved practices that become available to all firms in the industry. The last term, $v_{\mathrm{ijt}}$, captures any improvements in productivity resulting from firm-specific factors other than learning-by-doing.

Like the traditional learning curve, this approach is purely empirical and does not delve into the mechanisms of learning or even changes in firm behavior as a result of learning. Rather, it attempts to measure learning by attributing observed changes in firm performance to an observable proxy for prior experience. Though a very simple and stylized representation of the complex learning processes at play, we believe that the coefficient $\lambda$ so obtained can reasonably be interpreted as the importance of prior experience $\mathrm{X}$ in the production process. It also offers a number of other advantages, some of which are specific to our context.

First, our study is set in the US manufacturing sector, and it stands to reason that manufacturing processes would be important in determining overall firm performance. Hence, the notion of a "production function" makes intuitive sense and focusing on the importance of experience in the production process or on productivity improvement as a measure of learning is meaningful. Another advantage of this approach is that it controls for efficiency gains resulting from economies of scale. A traditional learning curve includes only the cumulative output, which could easily proxy for the scale of production (Argote, 1999, p.16). By including current levels of physical inputs in the specification, the production function approach controls for the possibility that economies of scale (which is a relation between current output and current inputs) rather than learning-by-doing (which depends on past output) is driving improvements. As explained above, this approach also allows us to control for the possibility that improvements 
in manufacturing processes are resulting from industry-wide improvements in technology rather than due to direct experience. This approach also has the nice property that under some reasonable assumptions, it is approximately equivalent to the traditional unit cost learning curve. Finally, compared to a traditional learning curve formulation, this approach involves variables that are more easily available. The main disadvantage is that these variables are usually available only at the plant level and not for individual products. Hence, the learning estimates obtained using this approach represent an average learning rate across products manufactured within a plant. ${ }^{3}$

\section{DATA AND EMPIRICAL ESTIMATION}

\section{Data}

The data for this study come from two sources: Compustat and the US Census Bureau. There are two stages of analyses in this paper. First, we use plant-level data from the US Census Bureau to estimate the learning coefficients for each industry. We then use these estimated industry learning coefficients as independent variables in regressions that use Compustat data to explore the impact of learning intensity on the heterogeneity of firm performance. These two data samples are described below.

\section{First Stage Plant-level Sample (Census Bureau Data)}

This sample is obtained from confidential micro-data available at the US Census Bureau. Since 1972, the US Census Bureau has been conducting a Census of Manufacturing (CM) every 5 years (there were two previous Censuses in 1963 and 1967). These censuses collect detailed

\footnotetext{
${ }^{3}$ As we explain later, we select our sample in a way to reduce the possibility of very different products being manufactured in the same plant.
} 
plant-level data from all US manufacturing establishments with at least one employee. The data collected generally include the value of plant shipments, materials and energy inputs, employment, production hours, payments to labor, book values of physical assets, capital expenditures, inventories and ownership (single plant firm v. part of a multi-plant firm). In addition, the US Census Bureau also performs an Annual Survey of Manufactures (ASM) that collects similar data from a sample of US manufacturing establishments. In particular, the annual surveys are designed to get an overview of the sector during the inter-census years and hence, place considerable weight on large plants and plants belonging to multi plant firms. To account for new entrants, a sample of new entrants is added to the ASM sample every year.

The Census Bureau has collated the data from all these censuses and surveys and linked them through a longitudinal identifier to create a dataset (sometimes called the Longitudinal Research Database or LRD), which it makes available to researchers at Census Research Data Centers, subject to access restrictions and disclosure constraints. The most important disclosure constraint is that no data that can identify or relate to a single firm or plant can be disclosed. Hence, in this paper, we do not identify statistics such as the median, minimum or maximum for variables obtained using Census Bureau data. For further details on this dataset, CM or ASM, please refer the US Census Bureau website.

Our sample is drawn from the LRD, which contains over 4 million plant-year observations from 1963 to 2001. Since the Census Bureau expends more effort on larger plants and firms, the quality of data for such cases is better. Also, they tend to have greater continuity of observations over time. In order to ensure reasonable data quality, we apply some sample selection criteria, the most important of which are: 
- Eliminating all plants that were established before 1973 or after 1997. 1973 is the first year of the annual ASM and it is not possible to reliably obtain the entry year for plants that first appear in the 1963, 1967 or 1972 Censuses. In 1997, the Census Bureau switched from the SIC to NAICS classification system. Hence, we excluded plants established after 1997 to minimize errors from industry misclassifications. ${ }^{4}$

- Excluding all subsequent observations for a plant if the gap between two consecutive survey years for that plant is more than two years. This is done to ensure a higher reliability of our main variable, prior cumulative output.

- Removing all plants that have a Primary Industry Specialization Ratio (the output share of the primary 4-digit SIC industry in the case of a multi-product plant) of less than $75 \%$. This is done to ensure homogeneity within an industry.

- Dropping outlier plants that are in the top 0.5 percentile of capital-labor ratio or of growth in number of employees, shipments or capital expenditure.

The resulting sample contains 182,603 plant-year observations. Summary statistics for this sample are provided in Table 1a.

\section{Second Stage Sample (Compustat Data)}

We use Compustat (limited to firms that have strictly positive assets) to obtain data for testing the relationship between learning by doing and performance heterogeneity. This sample is obtained by aggregating firm-year level data to the industry year level. First,we compute firm $q$ as the ratio of market value of assets to book value of assets, and firm profitability as the ratio

\footnotetext{
${ }^{4}$ The older plants that continued after 1997 were assumed to stay in the same SIC-4 code as they were in 1997. (Natarajan: this seems fairly obvious; is it necessary?)
} 
of operating profits before depreciation to total assets. ${ }^{5}$ We then eliminate all outlying observations in the top and bottom $1 \%$ in terms of firm $q$ or firm profitability. These data on firm performance are then aggregated to obtain the dispersion in firm $q$ and firm profitability for each SIC-3 digit industry in each year from 1973 to 2000 . We also obtained other industry level variables such as industry $R \& D$ and advertising intensity from Compustat. The industry classification was based on the primary industry code. The resulting sample contains 1,523 industry-year observations. Summary statistics for this sample are included in Table $1 \mathrm{~b}$.

Insert Table 1 about here

\section{Variables}

The important variables used in this study are described below. The first six pertain to the first stage plant-level sample and the last relates to the second stage industry-year sample.

Output. For any year before 1996, output for any plant is generally defined as the sum of the value of the plant's shipments (total plant revenues, deflated using SIC-4 industry-year deflators available on the NBER website) and the difference between year-beginning and yearending deflated work in process and deflated finished goods inventories. ${ }^{6}$ For years including and after 1996, due to the unavailability of inventory data, output is simply defined to be the

\footnotetext{
${ }^{5}$ Specifically, the definition of market value follows Kaplan and Zingales (1997).

${ }^{6}$ This definition is identical to that implicitly used by the Census Bureau in its computations of plant "value added" (see below). The Census Bureau uses slightly different definitions in some industries due to differences in the nature of the manufacturing processes. We follow the Census Bureau's definitions in all these cases. A detailed description is available on request.
} 
deflated shipments.

Value Added. Value Added is defined as the difference between real output and real materials (described below).

Labor. We define quantity of labor to be the labor hours expended in production worker equivalents. Labor hours for any plant are computed by dividing the total wage bill for the establishment by the average hourly wage for production workers in that establishment.

Materials. Real materials are defined as the sum of deflated cost of material purchases, external contract work, fuel and electricity.

Capital Stock and Capital Investment. We use the perpetual inventory approach to compute real capital stock. We compute separate stocks for buildings (or structures) and machinery. Real capital stock $\left(\mathrm{k}_{\mathrm{it}}\right)$ in any given year, say for machinery, is computed as $\mathrm{k}_{\mathrm{it}}=(1-$ d) $k_{i t-1}+I_{i t-1}+R_{i t}$ where $d$ is an industry-year specific depreciation rate for machinery, $I$ is the capital investment in machinery (deflated by an industry-year specific investment deflator for the year $t-1$ ) and $\mathrm{R}$ is the capitalized value of capital equipment rentals. If an establishment is not observed every year, following Olley and Pakes (1994) we impute gross investment linearly (i.e. $\mathrm{I}_{\mathrm{it}}=0.5^{*}\left(\mathrm{I}_{\mathrm{it}}+\mathrm{I}_{\mathrm{it}-\mathrm{n}}\right) *(\mathrm{n}-1)$, where $\mathrm{I}_{\mathrm{it}}$ is the imputed investment for period $\mathrm{t}$ and $\mathrm{n}$ is the gap between the two survey years).

Prior Cumulative Output. This is used as a proxy for accumulated operating experience. Prior cumulative output is defined as the sum of real output through the end of the previous period i.e. $\mathrm{X}_{\mathrm{it}}=\operatorname{sum}\left(\mathrm{o}_{\mathrm{i} 1}, \mathrm{o}_{\mathrm{i} 2} \ldots \mathrm{o}_{\mathrm{it}-1}\right)=\mathrm{X}_{\mathrm{it}-1}+\mathrm{o}_{\mathrm{it}-1}$, where $\mathrm{o}$ is real output If an establishment is not 
observed every year, we impute output linearly (i.e $\mathbf{O}_{\mathrm{it}}=0.5^{*}\left(\mathrm{o}_{\mathrm{it}}+\mathrm{o}_{\mathrm{it}-\mathrm{n}}\right) *(\mathrm{n}-1)$, where $\mathbf{O}_{\mathrm{it}}$ is the imputed output for period $\mathrm{t}$ and $\mathrm{n}$ is the gap between the survey years). ${ }^{7}$

Heterogeneity of Firm Performance. We use firm $q$ and firm profitability as measures of firm performance. Unlike most studies in the literature, we use direct measures of performance heterogeneity, specifically the cross-sectional dispersion of firm performance. We use three measures of cross-sectional dispersion of firm $q$ and firm profitability. As the baseline measure, we take the difference between the $90^{\text {th }}$ percentile and $10^{\text {th }}$ percentile (of firm $q$ or profitability) in an industry during a given year. The advantage of using this measure as opposed to say, variance is that it is an ordinal measure and hence, much less affected by the presence of outliers. As robustness checks, we use the inter-quartile range (or the difference between the $75^{\text {th }}$ and $25^{\text {th }}$ percentiles) and the standard deviation of firm profitability (or $q$ ) as other measures of heterogeneity.

\section{Empirical Estimation}

In the first part of our study, we use the Census data to estimate the learning rates for each SIC-3 industry and characterize the heterogeneity in industry learning rates. In the second part, which addresses the link between industry learning intensity and the heterogeneity of firm performance, we use the estimated industry-by-industry learning coefficients as explanatory variables in regressions with the range of firm performance as the dependent variable.

\footnotetext{
${ }^{7}$ This measure of experience does not incorporate "organizational forgetting" and hence, does not differentiate between a small, old firm and a large, young firm. As rough robustness checks, we estimated the learning coefficients using (i) the cumulative output till t-2 as a measure of experience and (ii) including plant age as another variable in Equation 9. The learning coefficients so estimated were highly correlated with our baseline estimates
} 
Measuring industry learning intensity. To proceed with empirical estimation of the importance of learning, we use OLS to estimate the logarithmic version of Equation (8):

$$
\mathrm{y}_{\mathrm{ijt}}=\mathrm{a}_{\mathrm{jt}}+\alpha_{\mathrm{j}} \cdot \mathrm{k}_{\mathrm{ijt}}+\beta_{\mathrm{j}} \cdot 1_{\mathrm{ijt}}+\lambda_{\mathrm{j}} \cdot \mathrm{x}_{\mathrm{ijt}}+\varepsilon_{\mathrm{ijt}}
$$

Where

$\mathrm{y}$ is $\log$ (Value Added), $\mathrm{k}, 1$, and $\mathrm{x}$ are, $\log (\mathrm{L}), \log (\mathrm{K})$ and $\log (\mathrm{X})$ respectively a is $\log (\varphi)$ and $\varepsilon$ includes $\log (v)$.

The coefficient of interest is $\lambda_{\mathrm{j}}$, the learning intensity of industry ${ }^{\mathrm{j}}{ }^{8} .{ }^{8}$ We estimate Equation (9) for each SIC-3 digit industry that has more than 50 plants. Estimating the production function industry-by-industry ensures that we are excluding the possibility that differences in returns to scale are being spuriously captured as learning. The terms $a_{j t}$ in Equation (9) are coefficients on industry-year dummies, which capture all inter-temporal movements in the average industry productivity, including any industry-wide technology improvements. Hence, the econometric identification of the coefficients comes solely from cross-sectional deviations from the industry-year averages and not from changes in mean industry productivity over time. ${ }^{9}$

\footnotetext{
${ }^{8}$ Since we treat the learning environment to be an industry characteristic, we estimate only one learning coefficient per industry. However, learning rates may change with time. As a robustness check, we estimated separate learning rates for the periods 1973-1984 and 1985-2000 (roughly equal sub-samples). The Spearman rank correlation between these two sets of coefficients was 0.54 and between these coefficients and our baseline estimates, 0.80 and 0.87 respectively, all statistically significant at or below the $0.01 \%$ level.

${ }^{9}$ One potential concern could be the bias in OLS estimates arising from the endogeneity of input choices, and survival bias. In order to address these concerns, we developed extensions of the Olley-Pakes (1994) and Ackerberg et al (2005) methods of production function estimation to estimate learning rates. Those
} 
Inter-industry heterogeneity in learning. It is difficult to obtain good empirical measures of process complexity for such a large sample. Hence, we rely on rather simple proxies that are easily available. Industries with greater capital-intensity have been associated with greater process complexity (Lieberman 1984). Also, it is reasonable to believe that R\&Dintensive industries have more complex processes and involve a higher degree of knowledge tacitness. Similarly, industries with high advertising intensity are likely to be differentiated, thus reducing the amount of learning that firms can achieve from their competitors. Finally, industry wages may reflect the underlying skill requirements and higher wages may proxy complexity.

To formally test hypothesis 1 , we adopt the following regression model, which includes these proxies interacted with $\mathrm{x}_{\mathrm{ijt}}$, the cumulative output measure:

$$
\mathrm{y}_{\mathrm{ijt}}=\mathrm{ajj}_{\mathrm{jt}}+\alpha \cdot \mathrm{k}_{\mathrm{ijt}}+\beta \cdot 1_{\mathrm{ijt}}+\lambda \cdot \mathrm{x}_{\mathrm{ijt}}+\lambda_{1} \cdot \mathrm{C}_{\mathrm{jt} .} \mathrm{x}_{\mathrm{ijt}}+\lambda_{2} \cdot \mathrm{W}_{\mathrm{jt} .} \mathrm{x}_{\mathrm{jij}}+\lambda_{3} \cdot \mathrm{R}_{\mathrm{jt} .} \mathrm{x}_{\mathrm{ijt}}+\lambda_{4} \cdot \mathrm{A}_{\mathrm{jt} .} \mathrm{x}_{\mathrm{ijt}}+\varepsilon_{\mathrm{ijt}}
$$

Where

$\mathrm{C}$ is industry capital intensity (capital stock to employment ratio);

$\mathrm{W}$ is industry wages;

$R$ is industry $R \& D$ intensity ( $R \& D$ expenditure divided by sales); and

A is industry advertising intensity (advertising expenditure divided by sales).

As in the industry-specific learning regressions, the unit of analysis is plant-year, and we allow for industry-year dummies $\mathrm{a}_{\mathrm{jt}}$. For this analysis, industry $\mathrm{R} \& \mathrm{D}$ and advertising data are obtained from Compustat. We use OLS to estimate Equation 10 with plant fixed effects and instrumental variables specifications as robustness checks.

estimates were highly correlated with the OLS estimates. More importantly, our primary results regarding firm performance heterogeneity remain robust to these alternative estimates (results available on request). 
Industry learning intensity and heterogeneity of firm performance. In order to examine how industry learning is related to heterogeneity of firm performance (Hypothesis 2), we use regressions of the following form:

$$
\pi_{\mathrm{jt}}=\mathrm{a}_{\mathrm{t}}+\mathrm{b} \cdot \underline{\lambda_{1}}+\mathrm{c}_{1} \cdot \mathrm{R}_{\mathrm{jt}}+\mathrm{c}_{2} \cdot \mathrm{A}_{\mathrm{jt}}+\mathrm{c}_{3} \cdot \mathrm{C}_{\mathrm{jt}}+\mathrm{c}_{4} \cdot \mathrm{S}_{\mathrm{jt}}+\mathrm{c}_{5} \cdot \mathrm{N}_{\mathrm{jt}}+\mathrm{c}_{6} \cdot \mathrm{P}_{\mathrm{jt}}+\varepsilon_{\mathrm{jt}}
$$

Where $\pi_{\mathrm{jt}}$ is $90^{\text {th }}$ to $10^{\text {th }}$ percentile range of firm performance, either firm $q$ or firm profitability, in industry $\mathrm{j}$ during year $\mathrm{t}$; $\underline{\underline{\lambda}}_{\mathrm{i}}$ is the estimated industry learning intensity from Equation (9); $\mathrm{R}$ is industry $\mathrm{R} \& \mathrm{D}$ intensity ( $\mathrm{R} \& \mathrm{D}$ expenditure/sales);

A is industry advertising intensity (advertising expenditure/sales);

$\mathrm{C}$ is industry capital intensity (total assets/sales);

$\mathrm{P}$ is average industry profitability (operating profits/ total assets);

$\mathrm{N}$ is the number of firms in an industry; and, $\mathrm{S}$ is industry size measured as total industry sales.

Note that the level of analysis here is the industry-year. For this analysis, we rely on data from Compustat; the only variable in Equation (11) that comes from outside Compustat is the estimated learning intensity.

A brief note on the choice of control variables is in order. Intuitively, our earlier arguments on the inter-industry heterogeneity in learning rates also apply to any factor that increases complexity. $R \& D$, advertising and capital intensity can logically be classified as such factors and would tend to increase the heterogeneity of firm performance. For instance, industries with high R\&D or high advertising intensity may be very differentiated and hence, performance more dispersed. Furthermore, these are sunk costs, which increase the incentives for firms to stay in the market once they have incurred those costs (Gschwandtner and Lambson 
2006), thereby increasing inter-firm heterogeneity. Average industry profitability may reflect inherent risk and hence, may be associated with a higher variance of returns. Finally, we add the number of firms and industry size as factors that may potentially increase measured heterogeneity.

\section{RESULTS}

\section{Inter-Industry Heterogeneity In Learning-By-Doing}

Table 2 presents the results of estimating Equation 9 for the pooled sample. Model 1 is a simple Cobb-Douglas production function, excluding the prior experience term that captures learning-by-doing. Model 2 expands on Model 1 by adding the prior experience term. The coefficient on prior cumulative output is 0.26 , which implies a $16 \%$ gain in productivity for each doubling of cumulative output. This model, however, does not control for the possibility that the rate of technological improvement varies across industries. For instance, firms in an industry with significant technological advances may show productivity improvements even without learning-by-doing. A robust approach to address this is to include a dummy variable for each industry-year combination, which will control for all inter-temporal changes (including technological improvements) in the average industry productivity. While our baseline definition of industry is at the SIC-3 digit level, the size of our pooled sample permits us to follow a far more conservative approach and use SIC-4 digit industry-year fixed effects. Model 3 includes 9,967 separate SIC-4 industry-year dummies, which control for all technological improvements in each SIC-4 industry (and consequently, in each SIC-3 industry). The estimated learning coefficient falls to 0.23 when these controls are added.

We then estimated Equation 9 using OLS for each of the 117 SIC-3 industries that has more than 50 plants. Models 4-1 to 4-117 allow each industry to have its own coefficients on 
capital, labor, and prior cumulative output. They also allow for year dummies within each SIC-3 industry and hence, control for SIC-3 industry-wide productivity improvements. Given space constraints, we present only the coefficients on cumulative output from these models in Appendix A (Column 3). Figure 3 presents a histogram of the coefficients on cumulative output. As expected, there is a significant variation in learning intensities across industries, ranging from just above 0 to almost 0.60 with an average of 0.22 (almost identical to the estimate for the pooled sample in Model 3).

Insert Figure 3 about here

Insert Table 2 about here

We now try to characterize the heterogeneity in learning intensity. From Appendix A, we can see that the top 6 industries based on the OLS learning coefficient are 357 (computers), 283 (pharmaceuticals), 291 (petroleum refining), 386 (photographic equipment \& supply), 287 (agricultural chemicals) and 289 (miscellaneous chemicals). The lowest in the list are 317 (leather goods) 322 (glass products), 262 (paper mills), 228 (yarn \& thread mills) and 311 (leather tanning). This list suggests a positive association between complex, knowledgeintensive and capital-intensive settings, and the rate of learning-by-doing.

To test this more formally, we estimate Equation 10 using OLS. Again, our pooled sample permits us to adopt a more conservative approach and use a finer SIC-4 digit industry definition. The variables of interest are the interaction terms between prior experience and 
industry factors. Models 5 and 6 in Table 3 use a larger sample for which we have complete data on industry wages and the capital-labor ratio, omitting the industry $R \& D$ and advertising intensity terms. Model 5 includes only year indicators while Model 6 includes a full set of industry-year dummies. In both cases, the learning coefficient is significantly higher in industries with greater capital intensity. The interaction effect of industry wages on prior experience becomes insignificant once industry-year effects are controlled for.

Model 7 estimates Equation (10) with a smaller data set for which we have complete industry $\mathrm{R} \& \mathrm{D}$ and advertising data from Compustat. The coefficient on prior experience is significantly higher in industries with higher capital-labor ratio and greater R\&D and advertising intensity. Models 5-7 assume that the coefficients on capital and labor are the same across industries; Model 8 repeats the tests in Model 7, allowing the coefficients on capital and labor to vary by SIC-2 digit industry. The results in Model 8 are not substantially different from Model 7. Finally, we estimate Models 9 and 10 to check if these results are robust to the inclusion of plant fixed effects. Model 9 does not include any of the direct terms while Model 10 includes them. While the effects decrease considerably in magnitude (as expected) in Model 9, the direction and statistical significance of the results persist. The significance of the interaction terms increase considerably when the direct terms are included. However, we must be cautious because the year-on-year changes in variables such as R\&D intensity are very small. Finally, we used an instrumental variables specification with once-lagged variables as instruments. The economic substance and statistical significance of these results (available on request) were very similar to those in Models 7 and $8 .^{10}$

\footnotetext{
${ }^{10}$ If as discussed earlier, the number of firms that "learn" decreases as the complexity increases, then we may observe low learning rates either because the true learning rate is low or because the process is so complex that few firms manage to "learn". However, such a situation would bias our empirical estimates on capital intensity, R\&D intensity etc. downward to zero rather than upward.
} 
To summarize, we find that the learning rate increases with industry capital intensity, $\mathrm{R} \& \mathrm{D}$ intensity, and advertising intensity, thus confirming hypothesis 1.

Insert Table 3 about here

\section{Industry Learning Intensity And Firm Performance Heterogeneity.}

We now examine the important question of how these variations in industry learning intensity are related to firm performance heterogeneity. Figure 4 gives an idea of the potential linkages. It presents the distributions of firm profitability and firm $q$ (relative to the industryyear average) for "high learning" (i.e. industries with learning rates above the median learning rate) and "low learning" industries. Figure 4 shows that both measures of firm performance have greater dispersion in "high learning" industries. To test this formally, we use the industry estimated learning coefficients (shown in Appendix A) as independent variables in Equation 8, with the range of firm performance within an industry as the dependent variable. Recall that the unit of analysis in Equation 8 is the firm-year but the industry-year.

Table 4 presents the results of estimating Equation 11 for our two measures of performance heterogeneity. Since all the variables except the learning coefficient have very skewed distributions, we use their logarithms rather than the original values. Model 11 uses the range of firm profitability as the dependent variable while Model 12 uses the range of firm $q$. The industry learning intensity coefficient is 0.926 in Model 11 . This implies that the difference between the "best performers" and the "worst performers" (as measured by relative profitability) is considerably greater in industries with high learning. Similar results hold when we use firm $q$ as a measure of firm performance. In both cases the coefficient on industry learning is positive 
and statistically significant at the $1 \%$ level.

Turning to the other coefficients in the regressions, sunk costs (particularly R\&D and advertising, and to an extent, capital intensity) are also positively linked to increased dispersion of firm performance. This is broadly in line with Gschwandtner and Lambson (2006), who found that sunk costs tend to increase profit variability in an industry, and theoretical industry models in the economics literature such as Hopenhayn (1992) that predict increased productivity dispersion due to higher sunk costs. ${ }^{11}$ The mean industry profitability appears to be associated with increased heterogeneity of firm value (which is consistent with a higher risk-higher return story) but rather counterintuitively, with decreased profitability dispersion. Another counterintuitive result is that large industries (by industry sales) tend to have lower heterogeneity. We do not have a good explanation for this except, perhaps, that they may be mature industries. Industries with many firms, in line with our intuition, show a wider dispersion.

Insert Table 4 about here

\section{Robustness Checks}

We performed a series of tests to confirm that we are most likely measuring the effect of learning-by-doing and that our subsequent results on the heterogeneity of firm performance are robust to alternative specifications. Briefly, the tests show that factors such as survivor bias, sample selection, R\&D investments, measurement errors in capital, choice of production

\footnotetext{
${ }^{11}$ In an unpublished working paper, Rivkin (2001) also finds that the dispersion of firm profit rates is higher in industries with opportunities for $R \& D$ and product differentiation.
} 
function form, and industry life cycle effects are not driving the observed heterogeneity in learning rates. The details are presented in Appendix B.

We tested the robustness of our results on the connection between learning and firm performance by running the same type of regressions as in Table 4, but with different measures of performance heterogeneity, level of aggregation, choice of time periods, assumptions about error correlation structures etc. Table B1 presents the coefficients on the learning estimates from those regressions. (Each line in Table B1 is comparable to line 1 from Table 4). In a majority of the regressions, learning shows a significant positive association with the heterogeneity of firm performance. Appendix B presents additional details.

\section{DISCUSSION AND CONCLUSION}

It is widely accepted and documented in the strategy literature that the industry environment affects competitive heterogeneity. In addition, many studies have shown that the rate of organizational learning varies greatly across firms and industries. Nevertheless, the connections between learning intensity and the industry competitive environment have not been systematically explored, given data limitations. Our paper provides quantitative evidence that supports the case for treating learning intensity as a fundamental characteristic of the industry,

much as R \& D and advertising. Furthermore, our paper facilitates empirical implementations of such a concept by providing reasonably comparable estimates of learning intensity for a wide range of industries, encompassing most of the US manufacturing sector.

To our knowledge, this study is the first to provide a quantitative comparison of learning rates across such a broad set of industries. The range of learning slopes from the OLS learning coefficients (computed as $2^{-\lambda}$, where $\lambda$ is the learning coefficient) varies from close to $100 \%$ (or no learning) in SIC 262 (Paper Mills) to a maximum of 68\% in SIC 283 (Drugs) and 66\% in SIC 
357 (Computers). ${ }^{12}$ This is comparable to the range of estimates in prior studies. For instance, the survey by Dutton and Thomas (1984) found that the median learning slope in about 22 industry-specific studies was about $80 \%$ and the range was from $55 \%$ to $110 \%$.

Our study goes beyond simply establishing the heterogeneity in learning rates to identify some broad patterns in these learning rates, as indicated in Table 3. Even within the limited interpretation permitted by our crude proxies, the results are consistent with the argument that learning from own experience may be more important in environments where complexity is high,. Knowledge transfers between firms, and perhaps even within firms, is naturally harder in such environments, and firms may have to rely more on their experience. Though intuitive, this study is the first attempt to quantify these patterns in a systematic way across a broad sample of industries.

The second contribution of our paper is to demonstrate a robust association between the industry learning intensity and the cross-sectional heterogeneity of firm performance. The results in Table 4 show that firm performance is more heterogeneous in high learning industries. More importantly, the economic significance of this effect seems to be large. Based on the coefficients in Model 11, an increase of one standard deviation in the learning coefficient (0.097) is associated with a $31 \%\left(=0.926^{*} 0.097 / 0.2891\right)$ increase in the profitability range. ${ }^{13}$ These are comparable to or even higher than the effect of an increase in R\&D or advertising intensity. For instance, using coefficients from Model 11, an increase in R\&D intensity by one standard deviation from the mean (i.e. from 0.0217 to 0.0443 ) is associated with a $12 \%$ $(=0.050 *[\ln (0.0443)-\ln (0.0217)] / 0.2891)$ increase in profitability range.

\footnotetext{
${ }^{12}$ A learning slope of $\mathrm{x} \%$ implies that a doubling of cumulative output leads to a $(100-\mathrm{x}) \%$ increase in productivity.

${ }^{13}$ Similar calculations using the Olley-Pakes and Ackerberg-Caves-Frazer methods yield estimates of 24\% and 29\%.
} 
As with all empirical studies, our analysis comes with a number of limitations. We adopt a highly aggregated view of learning by focusing on learning intensity at the industry level. Clearly, there is likely to be considerable heterogeneity in products and learning rates within industries, perhaps even greater than the inter-industry variations. Moreover, our study does not shed any light on the mechanisms of learning e.g. factors within organizations such as training and engineering activities (Adler and Clark, 1991), structures and routines (Nelson and Winter, 1982) that may affect learning. Furthermore, it is to be expected that the meaning and context of organizational learning vary significantly across (and within) industries. Since this paper follows a purely empirical approach and infers the importance of learning by examining the coefficient on cumulative output, the findings from this study are necessarily a very simplified and stylized representation of the learning environment. Furthermore, learning-by-doing is only one form of organizational learning (Levitt and March 1988; Malerba 1992). There are many other forms of learning such as learning from others, which are not examined in this study. Finally, there are measurement issues that commonly afflict studies of productivity estimation. Notwithstanding these limitations, we believe that this aggregate approach provides a "big picture" view of the heterogeneity in industry learning-environments that complements detailed micro-level studies of learning.

Although not a limitation, per se, the interpretation of the learning coefficient deserves some discussion. As we measure it, the learning coefficient does not reveal two aspects of learning that have been considered in prior studies. First, it does not tell anything about spillovers of learning across firms. Firms can apply experience gained from one product to cost reduction or quality improvements in other (perhaps, similar) products (Argote, 1999; Benkard, 2001; Irwin and Klenow, 1994) and it is reasonable to expect that learning "spills over" from one 
firm to another. In our approach, all improvements resulting from such industry-wide learning spillovers are captured by the industry-year dummy variables. As an extreme, an industry where some firms learn considerably from experience but all knowledge so generated is transferred to other firms immediately (thereby leaving the relative performances unchanged) would be measured as having a zero rate of learning. However, in such a case, learning rates would not affect firm performance and a "zero" learning coefficient would not entirely be meaningless. The second issue is organizational forgetting. It has been established that the knowledge accumulated through learning depreciates rapidly (Argote, 1999; Benkard, 2001). The use of a single learning coefficient clearly masks underlying differences in the rate of depreciation. A low learning coefficient could mean either a low learning rate combined with low rate of forgetting, or a high learning rate combined with rapid depreciation. Unfortunately, our data do not permit us to reliably estimate the rates of forgetting (nevertheless, see Appendix B for a rough robustness check). Even so, the learning coefficient can still be meaningfully interpreted as "net rate of learning" or as the "net importance" of experience in the production process.

The present study establishes basic relationships between industry learning and firm performance, but many extensions are possible. One would be to examine the mechanisms that explain the link between learning intensity and the heterogeneity of firm performance. We have provided some potential theoretical reasons for this association; however, their importance must be sorted out. More broadly, the learning estimates from this study can be used to analyze how variations in industry learning rates affect firm behavior. Strategic choices that may be affected by learning include incentive structures, governance structures, investments in innovation, capital and technology, and perhaps even organizational structures and processes. For instance, a bigger role for learning from experience may require an incentive structure oriented towards 
long-term performance goals rather than short-term ones. Another interesting line of inquiry would be to generalize our findings to examine how variations in the knowledge acquisition processes (e.g. through own learning vs. inter-firm spillovers vs. intra-firm spillovers etc.) across industries affect the observed heterogeneity.

Heretofore, researchers have been constrained by the non-availability of learning rate data across a wide range of industries needed to address such questions. This study provides industry specific estimates that may be used to further explore the role of learning by doing, particularly in broad, inter-industry contexts. We invite others to build upon this work.

\section{REFERENCES}

Ackerberg, D., Caves, K. and Frazer, G. Structural estimation of production functions: An application to the timing of input choices, mimeo, August 2005

Adler, P.S. \& Clark, K.B. 1991. Behind the learning curve: A sketch of the learning process. Management Science. 37: 267-281.

Argote L. 1999. Organizational learning: creating, retaining and transferring knowledge, Kluwer Academic Publishers.

Bahk, B.H. \& Gort M. 1993. Decomposing learning-by-doing in new plants, The Journal of Political Economy, 101: 561-583.

Barney, J. B. 1991. Firm resources and sustained competitive advantage, Journal of Management, 17: 99-120

Baum, J.A.C. \& Ingram, P. 1998. Survival-enhancing learning in the Manhattan hotel industry, 1898-1980. Management Science, 44: 996-1016.

Benkard, C.L. Learning and forgetting: The dynamics of aircraft production. American Economic Review, 90: 1034-1054.

Cohen, W.M. \& Levinthal, D.A. 1989 Innovation and learning: the two faces of R\&D. Economic Journal, 99: 569-596. 
Cohen, W.M. \& Levinthal, D.A. 1990 Absorptive capacity - a new perspective on learning and innovation. Administrative Science Quarterly, 35: 128-152.

Dierickx, I. \& Cool, L. 1989. Asset accumulation and sustainability of competitive advantage. Management Science, 35: 1504-1511

Dutton, J.M. \& Thomas, A. 1984. Treating progress functions as a managerial opportunity. Academy of Management Review, 9: 235-247.

Griliches Z. \& Mairesse, J. 1995. Production functions: the search for identification. Working paper no. 5067, National Bureau of Economic Research.

Gruber, H. 1994. The Yield Factor and the Learning Curve in Semiconductors. Applied Economics, 26: 225-248.

Gruber, H. 2000. The Evolution of Market Structure in Semiconductors: The Role of Product Standards. Research Policy 29: 725-740.

Gschwandtner, A. \& Lambson, V.E. 2006. Sunk costs, profit variability and turnover. Economic Inquiry, 44(2): 367-373

Hoopes, D.G., Madsen, T.L \& Walker, G. 2003. Guest editors' introduction to the special issue: Why is there a resource-based view? Toward a theory of competitive heterogeneity. Strategic Management Journal, 24: 889-902

Hopenhayn, H. 1992. Entry, exit and firm dynamics in the long run. Econometrica, 60(5): 11271150

Hayes, R.H. \& Clark, K.B. 1986 Why some factories are more productive than others. Harvard Business Review, 64(5): 66-73.

Irwin, D.A. \& Klenow, P.J. 1994. Learning-by-doing spillovers in the semiconductor industry. The Journal of Political Economy, 102: 1200-1227.

Jovanovic, B \& Nyarko Y, 1995. A Bayesian Learning Model Fitted to a Variety of Empirical Learning Curves, Brookings Papers on Economic Activity Microeconomics, 1995: 247-305

Kaplan, S.N. \& Zingales, L. 1997. Do investment-cash flow sensitivities provide useful measures of financing constraints? Quarterly Journal of Economics, 112(1): 169-215 
Levinthal, D.A. Adaptation on Rugged Landscapes. Management Science, 43(7): 934-950.

Levinthal, D.A. \& March, J.G. 1993. The myopia of learning. Strategic Management Journal, 14: 95-112.

Levitt, B. \& March, J.G. 1988. Organizational learning. Annual Review of Sociology. 14: 319340

Lieberman, M.B. 1984. The learning curve and pricing in the chemical processing industries. Rand Journal of Economics, 15(2): 213-228

Lieberman, M.B. 1987. The learning-curve, diffusion, and competitive strategy. Strategic Management Journal. 8: 441-452.

Lippman, S.A. \& Rumelt, R.P. 1982 Uncertain imitability - an analysis of interfirm differences in $\quad$ efficiency under competition. Bell Journal of Economics, 13: 418-438.

Malerba, F. 1992. Learning by firms and incremental technical change. Economic Journal, 102: 845-859.

Muth, J.F. 1986. Search theory and the manufacturing progress function. Management Science, 32: $948-962$

Nelson, R.R. \& Winter, S.G. An evolutionary theory of economic change. Harvard University Press. Cambridge, MA.

Olley,G.S. \& Pakes, A. 1996. The dynamics of productivity in the telecommunication equipment industry. Econometrica, 64(6): 1263-1297

Peteraf, M.A. 1993. The cornerstones of competitive advantage: a resource based view. Strategic Management Journal, 14(3): 179-191

Pisano G.P., Bohmer R.M.J. \& Edmondson A.C. 2001. Organizational differences in rates of learning: Evidence from the adoption of minimally invasive cardiac surgery. Management Science, 47: 752-768

Rapping, L. 1965. Learning and World War II production functions. Review of Economics and Statistics, 47: 81-86.

Rivkin, J.W. 2000. Imitation of complex strategies. Management Science, 46(6): 824-844 
Rivkin, J.W. 2001. Reconcilable Differences: The Relationship Between Industry Conditions and Firm Effects, Unpublished Doctoral Dissertation, Harvard Business School

Rumelt, R.P. 1991. How much industry matter? Strategic Management Journal, 12: 167-185

Schmalensee, R. Inter-industry studies of structure and performance. In R.Schmalensee and R.d. Willig (Eds.), Handbook of Industrial Organization, Vol II: 952-1009.

Sinclair, G., Klepper, S. \& Cohen, W. 2000. What's experience got to do with it? Sources of cost reduction in a large specialty chemicals producer. Management Science. 46: 28-45.

Spence, A.M. 1981 The learning curve and competition. Bell Journal of Economics, 12: 49-70

Thornton, R.A. \& Thompson, P. 2001. Learning from experience and learning from others: An exploration of learning and spillovers in wartime shipbuilding, American Economic Review, 91:1350-1368.

von Hippel, E. 1988. The Sources of Innovation. New York: Oxford University Press. 
Figure 1: Learning rate and complexity

\section{ENVIRONMENTAL NOISE $\left(\sigma^{2}{ }_{w}\right)$}

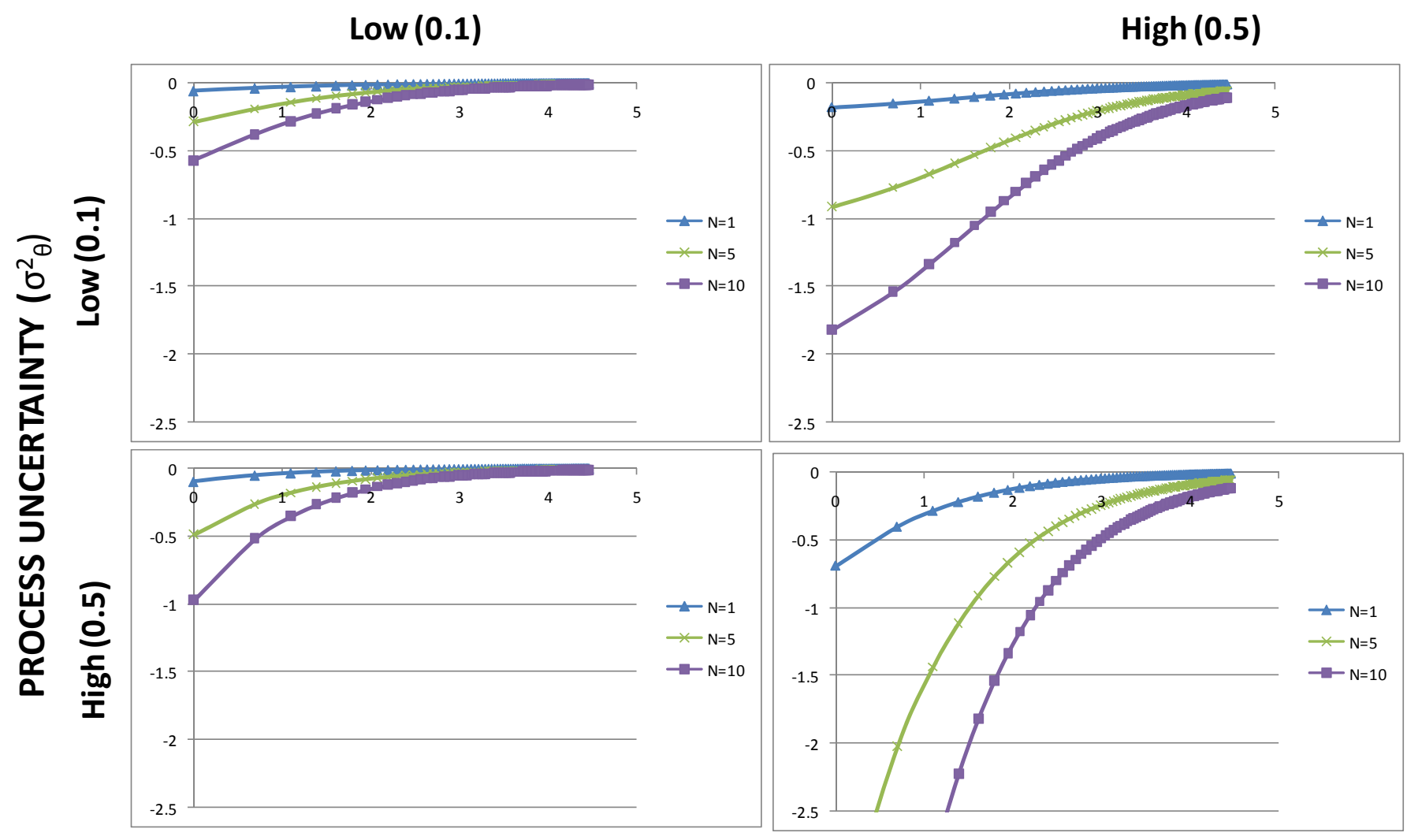

The horizontal axis in these graphs is the logarithm of the cumulative number of production runs. The vertical axis is the logarithm of the ratio of expected efficiency at any point in time to the eventual expected efficiency. 
Figure 2: Learning Rates and Performance Heterogeneity

\section{ENVIRONMENTAL NOISE $\left(\sigma^{2}{ }_{w}\right)$}

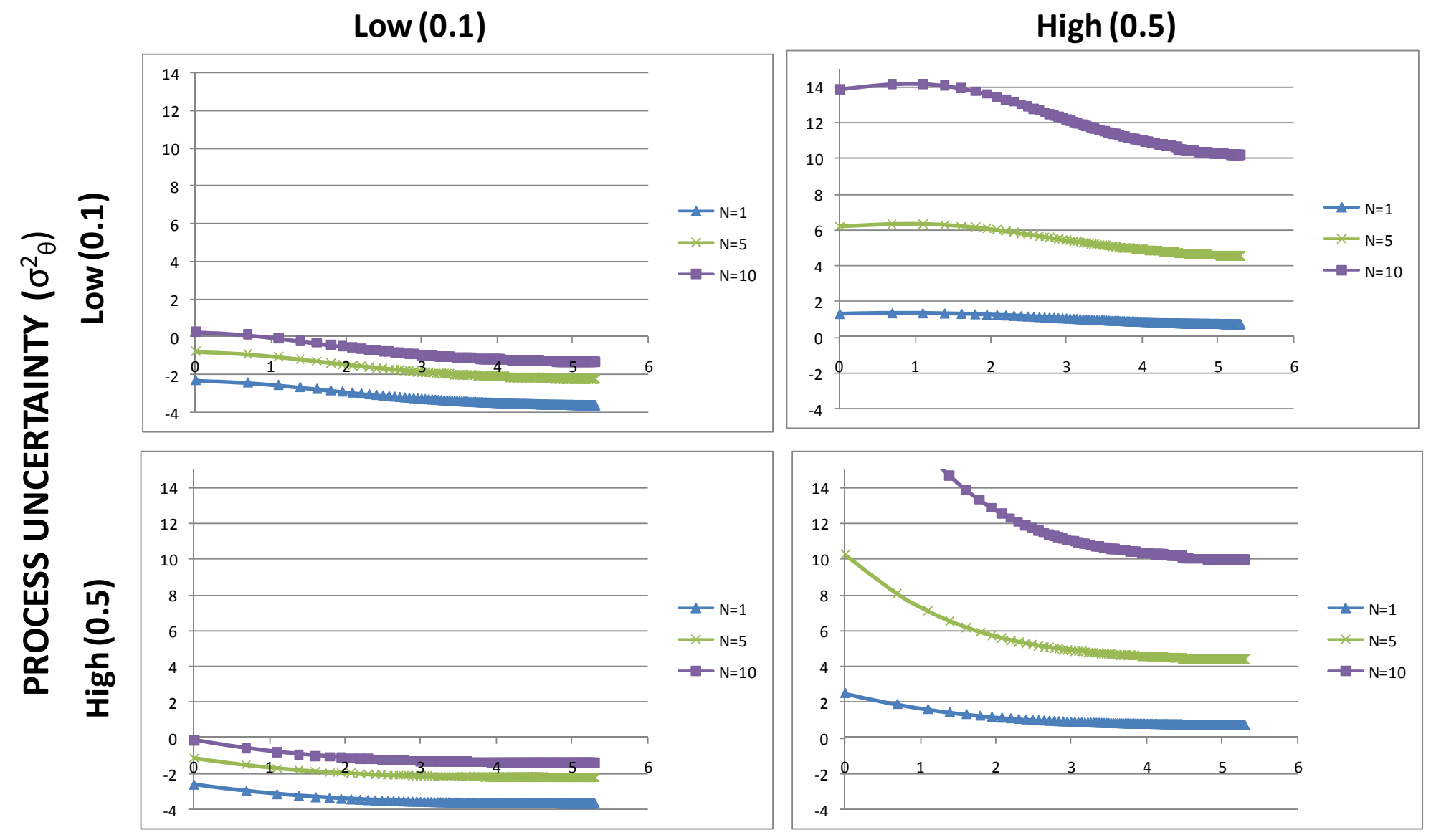

The horizontal axis in these graphs is the logarithm of the cumulative number of production runs. The vertical axis is the logarithm of the squared coefficient of variation of efficiencies. 
Figure 3: Inter-industry Heterogeneity in Learning-by-Doing

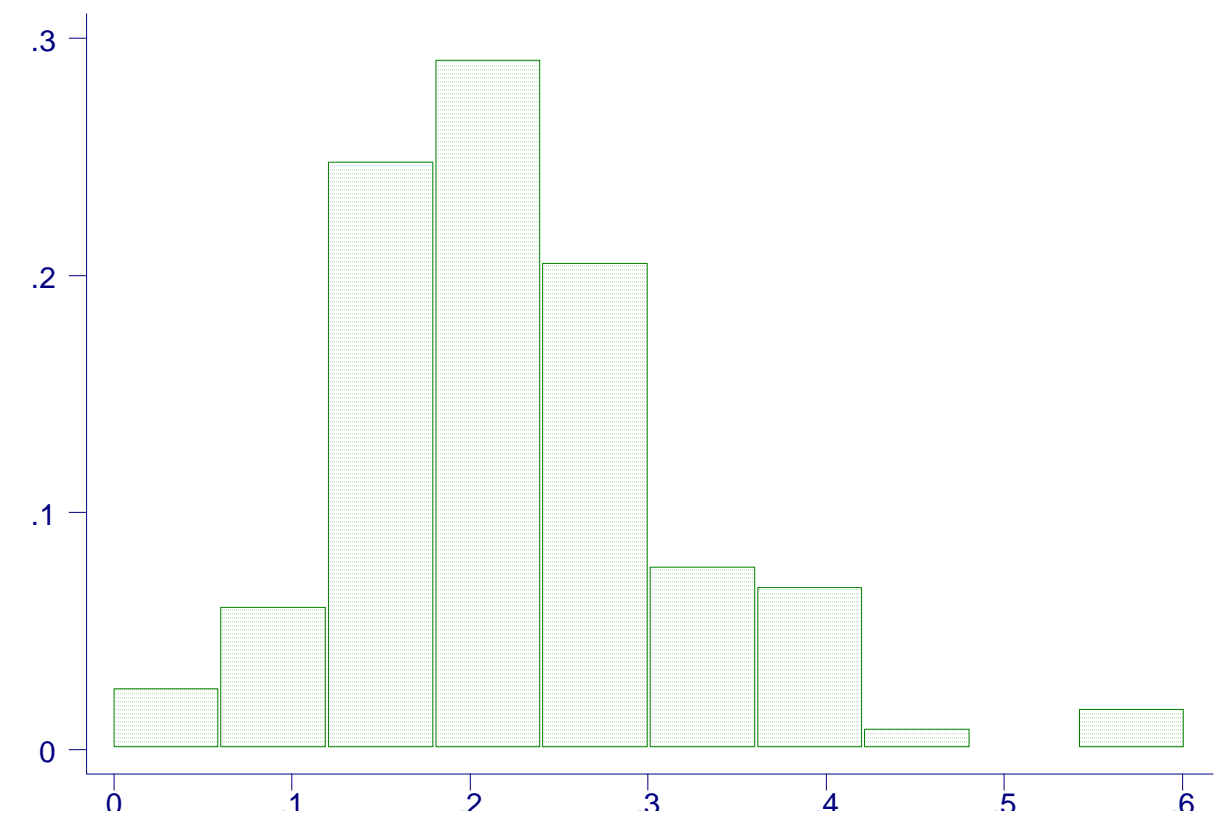


Figure 4: Industry Learning Environments and Firm Performance Heterogeneity

\section{Distribution of relative firm profitability}

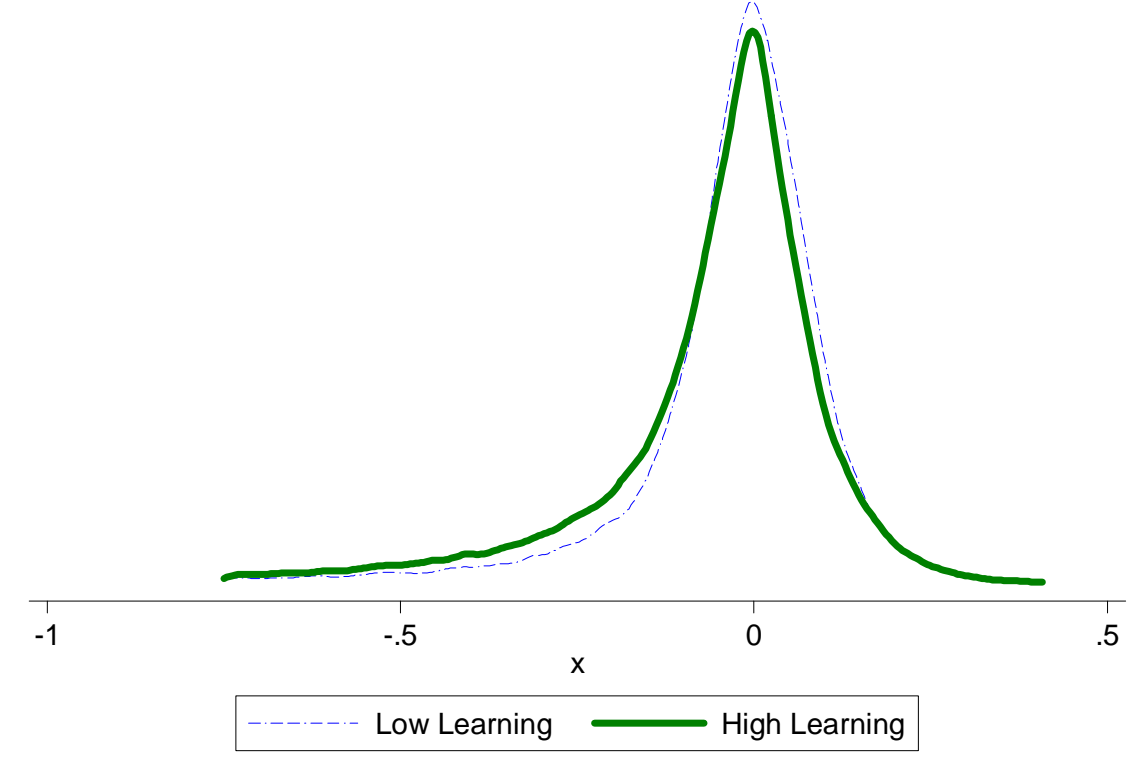

Distribution of relative firm q

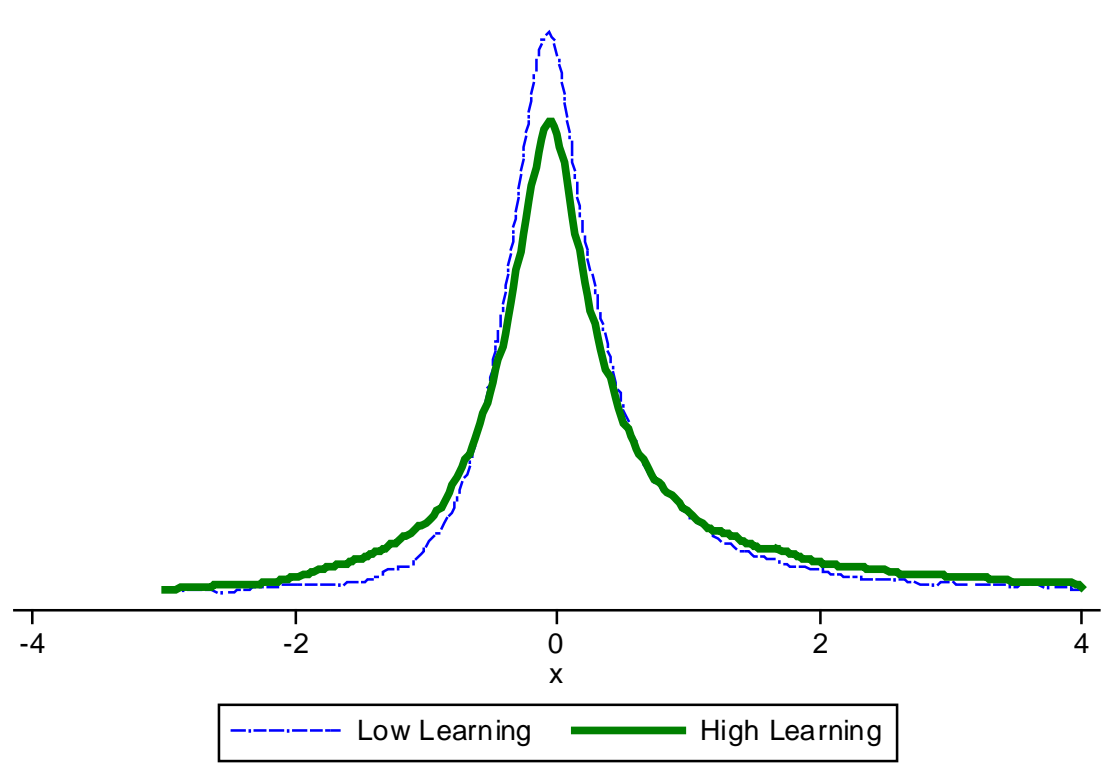


TABLE 1a

Overall Descriptive Statistics (Census or First Stage Sample) ${ }^{a}$

\begin{tabular}{|c|c|c|c|c|c|c|c|c|c|}
\hline Variable & Mean & s.d & Min & Max & 1 & 2 & 3 & 4 & \\
\hline 1. Value Added ${ }^{\mathrm{b}}$ & 7.40 & 1.86 & & & & & & & \\
\hline 2. Capital & 6.62 & 2.12 & & & $.77 * * *$ & & & & \\
\hline 3. Labor & 4.59 & 1.59 & & & $.85^{* * *}$ & $.75^{* * *}$ & & & \\
\hline 4. Material & 7.29 & 2.12 & & & $.81 * * *$ & $.77 * * *$ & $.79 * * *$ & & \\
\hline 5. Prior Experience & 9.21 & 2.24 & & & $.83^{* * *}$ & $.83^{* * *}$ & $.80 * * *$ & $.85 * * *$ & \\
\hline \multicolumn{10}{|c|}{$\begin{array}{c}\text { Table 1b } \\
\text { Overall Descriptive Statistics (Compustat or Second Stage Sample) }\end{array}$} \\
\hline 1. Industry R\&D intensity & 0.02 & 0.02 & 0.00 & 0.12 & & & & & \\
\hline $\begin{array}{l}\text { 2. Industry advertising } \\
\text { intensity }\end{array}$ & 0.02 & 0.02 & 0.00 & 0.08 & $-0.08 * * *$ & & & & \\
\hline 3. Number of firms & 44.15 & 51.31 & 10 & 453 & $0.72 * * *$ & $-0.09 * * *$ & & & \\
\hline 4. Industry sales ( $\$$ billion) & 47.59 & 140.40 & 0.44 & 1,498 & $0.12 * * *$ & $-0.10 * * *$ & $0.26 * * *$ & & \\
\hline $\begin{array}{l}\text { 5. Industry } q \text { range }\left(10^{\text {th }}-\right. \\
\left.90^{\text {th }} \text { pctile }\right)^{\mathrm{c}}\end{array}$ & 1.65 & 1.36 & 0.093 & 10.86 & $0.47 * * *$ & $0.16^{* * *}$ & $0.41 * * *$ & 0.03 & \\
\hline $\begin{array}{l}\text { 6. Industry profitability } \\
\text { range }\left(10^{\text {th }}-90^{\text {th }}\right)^{\mathrm{c}}\end{array}$ & 0.28 & 0.16 & 0.03 & 1.59 & $0.39 * * *$ & $0.07 * * *$ & $0.38 * * *$ & -0.01 & $0.63^{* *}$ \\
\hline
\end{tabular}

a. There are two separate samples. Table 1a refers to the first stage plant-level sample ( $\mathrm{n}=182,603$ of which 170,666 are in SIC-3 industries that have at least 50 plants) for which we are not able to present the minimum and maximum due to disclosure restrictions. Table $1 \mathrm{~b}$ refers to the second stage sample based on Compustat data $(\mathrm{n}=1,523)$

b. Variables 1-6 in Table 1a are logarithms of their original values. Please refer text for precise definition of variables.

$* p<0.1 * * p<0.05 * * * p<0.01$ 
TABLE 2

Pooled Learning Coefficients

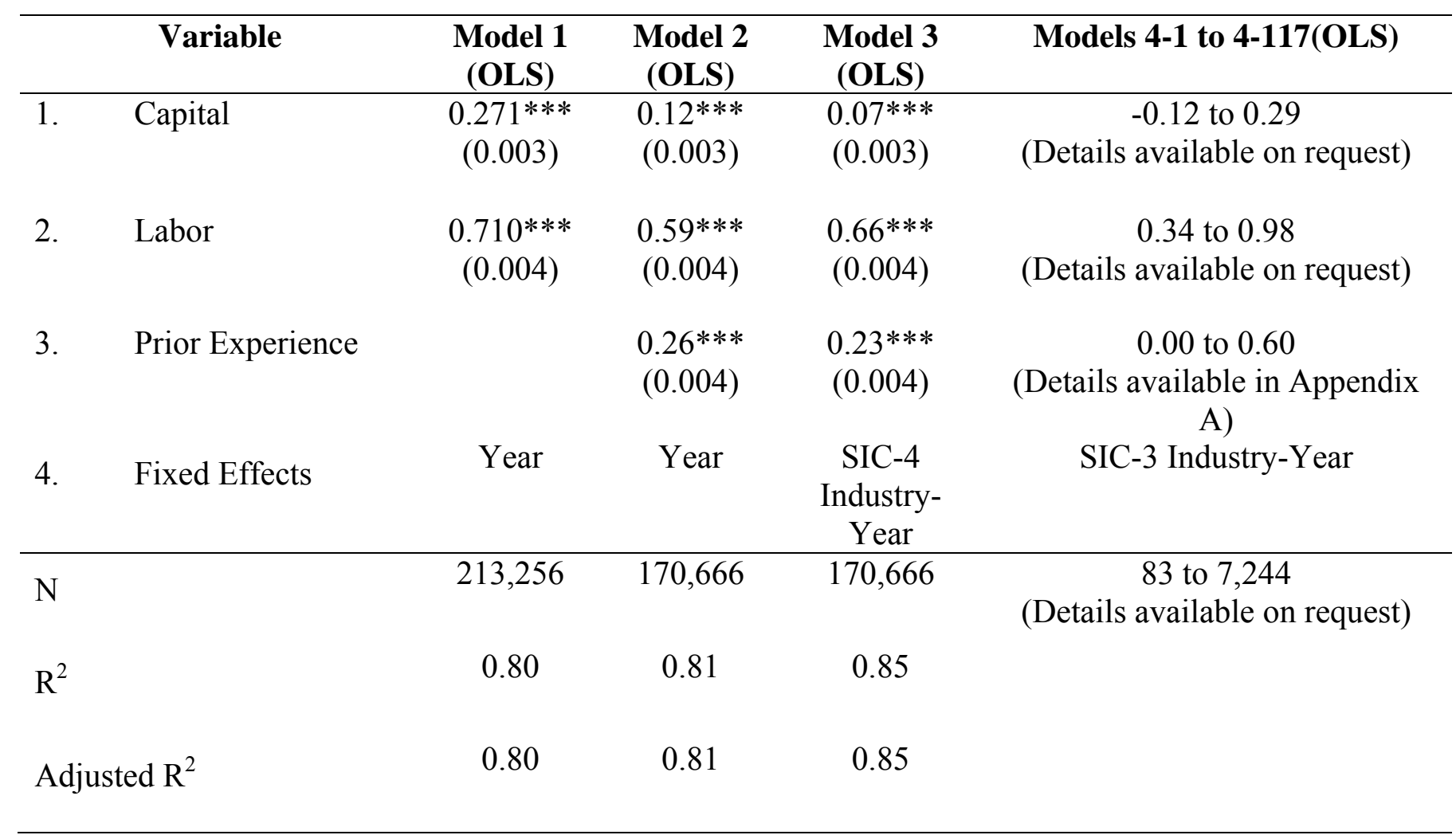

a. The unit of analysis is plant-year. Value added is the dependent variable. Coefficients on dummies not presented.

b. Models 4-1 to 4-117 are 117 separate OLS estimations along the lines of Model 2, one for each SIC-3 industry.

$* p<0.1 * * p<0.05 * * * p<0.01$. Robust standard errors in parentheses. 
TABLE 3: Inter-industry Heterogeneity in Learning-by-doing ${ }^{a}$

\begin{tabular}{|c|c|c|c|c|c|c|c|}
\hline & & $\begin{array}{c}\text { Model } 5 \\
\text { (OLS) }\end{array}$ & $\begin{array}{c}\text { Model } 6 \\
\text { (OLS) }\end{array}$ & $\begin{array}{c}\text { Model } 7 \\
\text { (OLS) }\end{array}$ & $\begin{array}{c}\text { Model 8 } \\
\text { (OLS) }\end{array}$ & $\begin{array}{c}\text { Model 9 } \\
\text { (FE) }\end{array}$ & $\begin{array}{c}\text { Model 10 } \\
\text { (FE) }\end{array}$ \\
\hline 1 & Capital & $\begin{array}{c}0.064 * * * \\
(0.003)\end{array}$ & $\begin{array}{c}0.074 * * * \\
(0.003)\end{array}$ & $\begin{array}{l}0.077 * * * \\
(0.005)\end{array}$ & By SIC-2 & By SIC-2 & By SIC-2 \\
\hline 2 & Labor & $\begin{array}{c}0.647 * * * \\
(0.004)\end{array}$ & $\begin{array}{c}0.665^{* * *} \\
(0.004)\end{array}$ & $\begin{array}{c}0.667 * * * \\
(0.007)\end{array}$ & By SIC-2 & By SIC-2 & By SIC-2 \\
\hline 3 & Prior Experience & $\begin{array}{c}0.250 * * * \\
(0.01)\end{array}$ & $\begin{array}{c}0.225^{* * *} \\
(0.01)\end{array}$ & $\begin{array}{c}0.198^{* * *} \\
(0.01)\end{array}$ & $\begin{array}{c}0.191 * * * \\
(0.01)\end{array}$ & $\begin{array}{c}0.066^{* * *} \\
(0.01)\end{array}$ & $\begin{array}{l}0.022^{*} \\
(0.01)\end{array}$ \\
\hline 4 & Experience*Industry Wages ${ }^{c}$ & $\begin{array}{c}-1.14 * * * \\
(0.31)\end{array}$ & $\begin{array}{l}-0.526 \\
(0.37)\end{array}$ & $\begin{array}{l}0.083 \\
(0.52)\end{array}$ & $\begin{array}{l}0.069 \\
(0.57)\end{array}$ & $\begin{array}{l}0.742 * * * \\
(0.14)\end{array}$ & $\begin{array}{c}0.036 \\
(0.475)\end{array}$ \\
\hline 5 & Experience $^{*}$ Industry Capital Labor Ratio ${ }^{c}$ & $\begin{array}{l}0.428 * * * \\
(0.05)\end{array}$ & $\begin{array}{l}0.323 * * * \\
(0.32)\end{array}$ & $\begin{array}{l}0.226^{* * *} \\
(0.06)\end{array}$ & $\begin{array}{c}0.266^{* * *} \\
(0.07)\end{array}$ & $\begin{array}{c}0.049 * * * \\
(0.01)\end{array}$ & $\begin{array}{c}0.424 * * * \\
(0.04)\end{array}$ \\
\hline 6 & Experience*Industry Advertising Intensity & & & $\begin{array}{l}0.869 * * * \\
(0.14)\end{array}$ & $\begin{array}{l}0.946 * * * \\
(0.16)\end{array}$ & $\begin{array}{c}0.156^{* * * *} \\
(0.03)\end{array}$ & $\begin{array}{c}0.553 * * * \\
(0.14)\end{array}$ \\
\hline 7. & Experience*Industry R\&D Intensity & & & $\begin{array}{l}0.446^{* * *} \\
(0.10)\end{array}$ & $\begin{array}{l}0.503 * * * \\
(0.11)\end{array}$ & $\begin{array}{c}0.037 * * * \\
(0.01)\end{array}$ & $\begin{array}{c}1.35^{* * * *} \\
(0.08)\end{array}$ \\
\hline 8 & Industry Wages & $\begin{array}{c}0.044 * * * \\
(0.003)\end{array}$ & & & & & $\begin{array}{l}0.004 \\
(0.01)\end{array}$ \\
\hline 9 & Industry Capital Labor Ratio ${ }^{c}$ & $\begin{array}{c}-0.036^{* * * *} \\
(0.004)\end{array}$ & & & & & $\begin{array}{c}-0.446^{* * *} \\
(0.04)\end{array}$ \\
\hline & Industry R\&D Intensity ${ }^{\mathrm{d}}$ & & & & & & $\begin{array}{c}-0.149 * * * \\
(0.01)\end{array}$ \\
\hline & Industry Advertising Intensity ${ }^{\mathrm{d}}$ & & & & & & \\
\hline & Fixed Effects & Year & Industry-Year & Industry-Year & Industry-Year & Plant \& Year & Plant \& Year \\
\hline $\mathrm{N}$ & & 182,603 & 182,603 & 71,824 & 71,824 & 71,824 & 71,824 \\
\hline $\mathrm{R}^{2}$ & & 0.82 & 0.83 & 0.83 & 0.83 & 0.91 & 0.93 \\
\hline
\end{tabular}

a. The unit of analysis is plant-year. Log value added is the dependent variable. Coefficients on dummies not presented.With industry-year effects, direct terms are not included because the dummies control for all changes at the industry-year level (e.g. industry R\&D intensity).

b. Models 8 to 10 allow for industry-specific (by SIC-2) capital and labor coefficients. Given the large number of capital and labor coefficients, we do not present them here.

c. Coefficients and standard errors divided by 1000 for presentation purposes.

d. Coefficients and standard errors divided by 100 for presentation purposes.

${ }^{*} p<0.1{ }^{* *} p<0.05 * * p<0.01$. Robust standard errors in parentheses. 
TABLE 4

Learning-by-doing and Heterogeneity in Firm Performance ${ }^{a}$

\begin{tabular}{|c|c|c|}
\hline & Model 11 & Model 12 \\
\hline Dependent Variable & $\begin{array}{c}\text { Profit } \\
\text { Dispersion }\end{array}$ & $\underset{\text { dispersion }}{q}$ \\
\hline 1. Industry Learning & $\begin{array}{c}0.926 * * * \\
(0.10)\end{array}$ & $\begin{array}{l}1.41 * * * \\
(0.14)\end{array}$ \\
\hline 2. Industry R\&D & $0.050 * * *$ & $0.102 * * *$ \\
\hline $\begin{array}{l}\text { 3. Industry Advertising } \\
\text { Intensity }\end{array}$ & $\begin{array}{c}0.040 * * * \\
(0.01)\end{array}$ & $\begin{array}{l}0.070 * * * \\
(0.01)\end{array}$ \\
\hline $\begin{array}{l}\text { 4. Industry Profitability } \\
\text { (Mean) }\end{array}$ & $\begin{array}{c}-0.131 * * * \\
(0.04)\end{array}$ & $\begin{array}{c}0.207 * * * \\
(0.05)\end{array}$ \\
\hline $\begin{array}{l}\text { 5. Industry Capital } \\
\text { Intensity }\end{array}$ & $\begin{array}{c}-0.110^{* *} \\
(0.05)\end{array}$ & $\begin{array}{l}0.113^{*} \\
(0.06)\end{array}$ \\
\hline 6. Industry Sales & $\begin{array}{l}-0.117 * * * \\
\quad(0.01)\end{array}$ & $\begin{array}{c}-0.117 * * * \\
(0.01)\end{array}$ \\
\hline $\begin{array}{l}\text { 7. Industry Number of } \\
\text { Firms }\end{array}$ & $\begin{array}{l}0.251 * * * \\
(0.02)\end{array}$ & $\begin{array}{l}0.268 * * * \\
(0.02)\end{array}$ \\
\hline 8. Fixed Effects & Year & Year \\
\hline $\mathrm{N}$ & 1,523 & 1,523 \\
\hline $\mathrm{R}^{2}$ & 0.38 & 0.55 \\
\hline Adjusted $\mathrm{R}^{2}$ & 0.37 & 0.54 \\
\hline
\end{tabular}

a. The unit of analysis in all these regressions is SIC-3 industry-year. All variables except the industry learning intensity are logarithms of their original values. The dependent variable is the (logarithm of) difference between $90^{\text {th }}$ and $10^{\text {th }}$ percentiles of either firm profitability or firm q. Coefficients on dummies not presented.

${ }^{*} p<0.1 * * p<0.05 * * * p<0.01$. Robust standard errors in parentheses. 
APPENDIX A: INDUSTRY-BY-INDUSTRY LEARNING COEFFICIENTS

\begin{tabular}{|c|c|c|c|}
\hline \multirow[t]{2}{*}{ SIC } & \multirow{2}{*}{$\begin{array}{c}\text { Rank } \\
\text { (OLS) }\end{array}$} & \multicolumn{2}{|c|}{ OLS } \\
\hline & & Coeff. & $\begin{array}{c}\text { Std } \\
\text { Error }\end{array}$ \\
\hline 201 & 99 & 0.148 & $(0.02)$ \\
\hline 202 & 79 & 0.180 & $(0.02)$ \\
\hline 203 & 18 & 0.321 & $(0.02)$ \\
\hline 204 & 30 & 0.273 & $(0.02)$ \\
\hline 205 & 23 & 0.294 & $(0.02)$ \\
\hline 206 & 58 & 0.207 & $(0.04)$ \\
\hline 207 & 17 & 0.323 & $(0.04)$ \\
\hline 208 & 21 & 0.300 & $(0.02)$ \\
\hline 209 & 38 & 0.260 & $(0.02)$ \\
\hline 221 & 101 & 0.145 & $(0.07)$ \\
\hline 222 & 77 & 0.181 & $(0.04)$ \\
\hline 224 & 98 & 0.151 & $(0.08)$ \\
\hline 225 & 72 & 0.187 & $(0.02)$ \\
\hline 226 & 94 & 0.163 & $(0.03)$ \\
\hline 227 & 16 & 0.326 & $(0.05)$ \\
\hline 228 & 116 & 0.041 & $(0.03)$ \\
\hline 229 & 55 & 0.213 & $(0.03)$ \\
\hline 231 & 26 & 0.284 & $(0.04)$ \\
\hline 232 & 92 & 0.165 & $(0.02)$ \\
\hline 233 & 29 & 0.278 & $(0.01)$ \\
\hline 234 & 46 & 0.241 & $(0.04)$ \\
\hline 235 & 32 & 0.271 & $(0.08)$ \\
\hline 236 & 40 & 0.254 & $(0.03)$ \\
\hline 238 & 35 & 0.266 & $(0.04)$ \\
\hline 239 & 25 & 0.286 & $(0.02)$ \\
\hline 241 & 56 & 0.213 & $(0.01)$ \\
\hline 242 & 64 & 0.202 & $(0.01)$ \\
\hline 243 & 61 & 0.205 & $(0.01)$ \\
\hline 244 & 110 & 0.093 & $(0.02)$ \\
\hline 245 & 109 & 0.108 & $(0.02)$ \\
\hline 249 & 82 & 0.177 & $(0.02)$ \\
\hline 251 & 87 & 0.170 & $(0.01)$ \\
\hline 252 & 67 & 0.198 & $(0.03)$ \\
\hline 253 & 76 & 0.182 & $(0.04)$ \\
\hline 254 & 96 & 0.154 & $(0.02)$ \\
\hline 259 & 53 & 0.215 & $(0.03)$ \\
\hline 262 & 115 & 0.054 & $(0.04)$ \\
\hline 265 & 69 & 0.192 & $(0.01)$ \\
\hline 267 & 37 & 0.260 & $(0.03)$ \\
\hline 281 & 20 & 0.310 & $(0.02)$ \\
\hline 282 & 9 & 0.385 & $(0.03)$ \\
\hline
\end{tabular}


Industry Learning Environments and the Heterogeneity of Firm Performance 45

\begin{tabular}{|c|c|c|c|}
\hline \multirow[t]{2}{*}{ SIC } & \multirow{2}{*}{$\begin{array}{r}\text { Rank } \\
\text { (OLS) }\end{array}$} & \multicolumn{2}{|c|}{ OLS } \\
\hline & & Coeff. & $\begin{array}{c}\text { Std } \\
\text { Error }\end{array}$ \\
\hline 283 & 2 & 0.547 & $(0.03)$ \\
\hline 284 & 10 & 0.372 & $(0.03)$ \\
\hline 285 & 15 & 0.342 & $(0.03)$ \\
\hline 286 & 8 & 0.388 & $(0.03)$ \\
\hline 287 & 6 & 0.413 & $(0.03)$ \\
\hline 289 & 5 & 0.413 & $(0.02)$ \\
\hline 291 & 3 & 0.451 & $(0.10)$ \\
\hline 295 & 52 & 0.224 & $(0.02)$ \\
\hline 299 & 11 & 0.369 & $(0.05)$ \\
\hline 305 & 19 & 0.313 & $(0.05)$ \\
\hline 306 & 88 & 0.169 & $(0.02)$ \\
\hline 308 & 48 & 0.237 & $(0.01)$ \\
\hline 311 & 117 & 0.005 & $(0.07)$ \\
\hline 313 & 39 & 0.256 & $(0.09)$ \\
\hline 314 & 43 & 0.246 & $(0.03)$ \\
\hline 316 & 103 & 0.144 & $(0.08)$ \\
\hline 317 & 113 & 0.076 & $(0.07)$ \\
\hline 319 & 104 & 0.127 & $(0.07)$ \\
\hline 321 & 78 & 0.181 & $(0.05)$ \\
\hline 322 & 114 & 0.067 & $(0.03)$ \\
\hline 323 & 73 & 0.185 & $(0.02)$ \\
\hline 324 & 7 & 0.389 & $(0.08)$ \\
\hline 325 & 12 & 0.360 & $(0.03)$ \\
\hline 326 & 97 & 0.152 & $(0.03)$ \\
\hline 327 & 36 & 0.265 & $(0.01)$ \\
\hline 328 & 31 & 0.272 & $(0.04)$ \\
\hline 329 & 14 & 0.354 & $(0.02)$ \\
\hline 331 & 90 & 0.169 & $(0.02)$ \\
\hline 332 & 85 & 0.172 & $(0.02)$ \\
\hline 333 & 45 & 0.241 & $(0.05)$ \\
\hline 334 & 54 & 0.214 & $(0.05)$ \\
\hline 335 & 68 & 0.194 & $(0.02)$ \\
\hline 336 & 33 & 0.269 & $(0.03)$ \\
\hline 339 & 106 & 0.123 & $(0.03)$ \\
\hline 341 & 22 & 0.299 & $(0.02)$ \\
\hline 342 & 75 & 0.184 & $(0.02)$ \\
\hline 343 & 59 & 0.207 & $(0.03)$ \\
\hline 344 & 80 & 0.178 & $(0.01)$ \\
\hline 345 & 74 & 0.184 & $(0.02)$ \\
\hline 346 & 84 & 0.173 & $(0.02)$ \\
\hline 347 & 63 & 0.202 & $(0.01)$ \\
\hline 348 & 83 & 0.174 & $(0.05)$ \\
\hline 349 & 71 & 0.189 & $(0.01)$ \\
\hline
\end{tabular}


Industry Learning Environments and the Heterogeneity of Firm Performance 46

\begin{tabular}{|c|c|c|c|}
\hline \multirow[t]{2}{*}{ SIC } & \multirow{2}{*}{$\frac{\text { Rank }}{\text { (OLS) }}$} & \multicolumn{2}{|c|}{ OLS } \\
\hline & & Coeff. & $\begin{array}{c}\text { Std } \\
\text { Error }\end{array}$ \\
\hline 351 & 86 & 0.170 & $(0.04)$ \\
\hline 353 & 89 & 0.169 & $(0.02)$ \\
\hline 354 & 62 & 0.202 & $(0.01)$ \\
\hline 355 & 51 & 0.227 & $(0.02)$ \\
\hline 356 & 47 & 0.237 & $(0.01)$ \\
\hline 357 & 1 & 0.602 & $(0.03)$ \\
\hline 358 & 44 & 0.246 & $(0.02)$ \\
\hline 359 & 93 & 0.163 & $(0.01)$ \\
\hline 361 & 24 & 0.290 & $(0.02)$ \\
\hline 362 & 66 & 0.200 & $(0.02)$ \\
\hline 363 & 105 & 0.126 & $(0.04)$ \\
\hline 364 & 49 & 0.233 & $(0.02)$ \\
\hline 365 & 107 & 0.122 & $(0.04)$ \\
\hline 366 & 50 & 0.229 & $(0.03)$ \\
\hline 367 & 13 & 0.355 & $(0.02)$ \\
\hline 369 & 28 & 0.278 & $(0.02)$ \\
\hline 371 & 70 & 0.191 & $(0.01)$ \\
\hline 372 & 95 & 0.157 & $(0.02)$ \\
\hline 373 & 108 & 0.108 & $(0.02)$ \\
\hline 374 & 102 & 0.144 & $(0.05)$ \\
\hline 375 & 91 & 0.166 & $(0.06)$ \\
\hline 379 & 112 & 0.091 & $(0.02)$ \\
\hline 381 & 27 & 0.280 & $(0.07)$ \\
\hline 382 & 81 & 0.178 & $(0.02)$ \\
\hline 384 & 34 & 0.267 & $(0.02)$ \\
\hline 385 & 111 & 0.093 & $(0.04)$ \\
\hline 386 & 4 & 0.416 & $(0.04)$ \\
\hline 391 & 42 & 0.250 & $(0.03)$ \\
\hline 393 & 100 & 0.146 & $(0.04)$ \\
\hline 394 & 41 & 0.251 & $(0.02)$ \\
\hline 395 & 65 & 0.202 & $(0.05)$ \\
\hline 396 & 57 & 0.209 & $(0.04)$ \\
\hline 399 & 60 & 0.206 & $(0.02)$ \\
\hline Mean & & 0.227 & \\
\hline Std. Dev & & 0.097 & \\
\hline Min & & 0.005 & \\
\hline Max & & 0.602 & \\
\hline
\end{tabular}




\section{APPENDIX B: ROBUSTNESS CHECKS}

\section{Are we measuring learning-by-doing?}

We tested if there are other phenomena that manifest as a high coefficient on cumulative output. While we cannot rule all possible alternatives out, we attempt to identify and argue against some important ones.

Survivor Bias and Sample Selection: With OLS, endogeneity of exit may bias the measured coefficient on cumulative output. If accumulated experience helps firms withstand bad "performance shocks" and thus reduces the probability of exit, then the measured coefficient will be biased downward. On the other hand, if accumulated experience has no effect on exit, then the bias may be upward, the argument being that only "good" firms survive and they would tend to have both higher cumulative output and higher productivity, resulting in a high "learning" coefficient. However, these arguments does not appear to hold in our study for several reasons. If this argument were true, we should see a strong positive correlation between the turnover rate of firms (entry rate + exit rate) and our measured "learning". However, we see no statistically significant relationship between industry turnover rate and the measured learning rate (results available on request). Also, the Olley-Pakes and Ackerberg estimates that correct for these potential biases are highly correlated with estimates presented here (results available on request).

We also tested the robustness of our results to the choice of our sample. Using a sample that includes only ASM plants (which have better quality data) and relaxing our condition that plants not have a gap of more than 2 years between two consecutive years produced learning estimates that were highly correlated with our baseline estimates (results available on request).

$R \& D$ investments: Sinclair et al (2000) argue that it is specific R\&D efforts that cause learning-by-doing. If all the learning were due to $\mathrm{R} \& \mathrm{D}$, we should observe no learning once we 
include $R \& D$ as a control. Without controlling for $R \& D$, we would observe high $R \& D$ industries to have high learning. Since the industries with high measured learning in our study are $R \& D$ intensive industries, we attempt to rule out $R \& D$ as solely driving the results. However, we lack detailed data on plant-level $R \& D$ and hence, we use firm-level R\&D from Compustat as controls and re-estimate the learning coefficients. The rank correlation between this set of learning coefficients and our original estimates is 0.67 and statistically significant at the $0.01 \%$ level. Furthermore, using these revised learning coefficients did not change the subsequent results on firm performance heterogeneity (Row 17 in Table B1).

Measurement errors in capital: It is well known that there are errors with measuring capital. If it were true that such measurement errors were more prevalent in some industries (e.g. in hi-tech industries), then we may observe a high measured rate of learning in such industries. While there is no known way to completely rule this out, we re-estimate our learning coefficients using an alternative measure of capital instead of the perpetual inventory method used in the study. Specifically, we use the year-end book value of assets and find that the resulting learning coefficients are highly correlated with our original estimates.

Industry life cycles: The need for learning-by-doing may be intricately linked to industry life cycles. For instance, early in the industry life cycle, firms may need to learn mostly on their own. Furthermore, this is also a period of great uncertainty and consequently higher heterogeneity of performance. As the industry matures, dominant design(s) emerge and firms may be able to benefit from others, thereby reducing the need for own learning. Concomitantly, the uncertainty also decreases, reducing performance heterogeneity. While this is certainly consistent with our arguments (note that we do not make any exhaustive claims over what gives 
rise to learning-by-doing), that we find exit rates to be uncorrelated with learning intensities suggests that industry life cycles are not the sole driving factor here.

Alternative production functions: We tested the robustness to relaxing the Cobb-Douglas production function form adopted here. Specifically, we estimated using OLS, a version of the

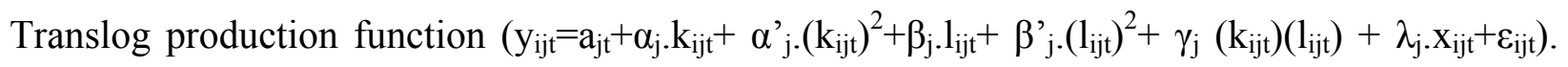
These learning coefficients were highly correlated with our baseline estimates.

\section{Learning-by-doing and heterogeneity of firm performance}

Table B1 presents the results of robustness checks on this aspect.

Alternative measures of heterogeneity: So far, we have used the difference between the $90^{\text {th }}$ and $10^{\text {th }}$ percentiles as the measure of firm performance heterogeneity. Rows 1 and 2 use the inter-quartile range (difference between the $75^{\text {th }}$ and $25^{\text {th }}$ percentiles) and standard deviation of firm performance respectively. We observe that the coefficient on learning intensity is strongly positive in all but one specification.

Ordinal measures of learning intensity: In our baseline results, we directly used the estimated learning intensities as measures of learning-by-doing. Since the estimated learning intensities vary across different specifications, we check if using ordinal measures makes a difference. Row 3 uses the industry learning ranks (based on the estimated learning coefficient) instead of the estimated learning intensities. Row 4 uses a simple dummy variable that divides industries into "high learning" and "low learning" based on the median estimated learning coefficients. Once again, the results are statistically significant in almost all specifications.

Excluding diversified firms: Our results use the firm's primary SIC code to assign firms to industries. However, many firms in Compustat are diversified and hence, it may be argued that it is inappropriate to use a single learning coefficient for such firms. Using the Compustat 
business segments data from 1984 to 2000, we select firms that have a single SIC-3 segment that comprises at least $95 \%$ of their total sales and estimate Equation 5 for these firms. Row 5 presents the results. The results are strongly positive and statistically insignificant.

Level of aggregation: Since it may be argued that SIC-3 digit is a very high level of aggregation, we estimate learning intensity at the SIC-4 digit level using OLS and repeat our test. Row 6 shows that even with a finer industry definition, our results hold. Another possible concern is that the definition of some SIC-3 industries are simply much more heterogeneous than others. To rule this possibility out, (a) we excluded all SIC-3 industries ending with "9" (usually "not elsewhere classified" industries) and (b) included the number of SIC-4 digit codes within a SIC-3 as a control in Equation 5. The results remained statistically significant (Row 7) for most specifications.

Other econometric concerns: Rows 8 to 16 provide results to alleviate other possible econometric concerns such as errors being correlated within an industry (check: cluster errors within an industry), taking logarithms (checks: not taking logarithms at all and not taking logarithms for the dependent variable), the choice of 10 firms in an industry-year as the cut-off for inclusion (check: use 25 firms as cut-off), influence of outliers (check: exclude the top two and bottom industries in terms of learning rates, choice of time period (check: separate 19731984 and 1985-2000), other unobserved industry factors (check: joint SIC2-year dummies). The results remain statistically significant for a major part of these alternative specifications. 


\section{TABLE B1}

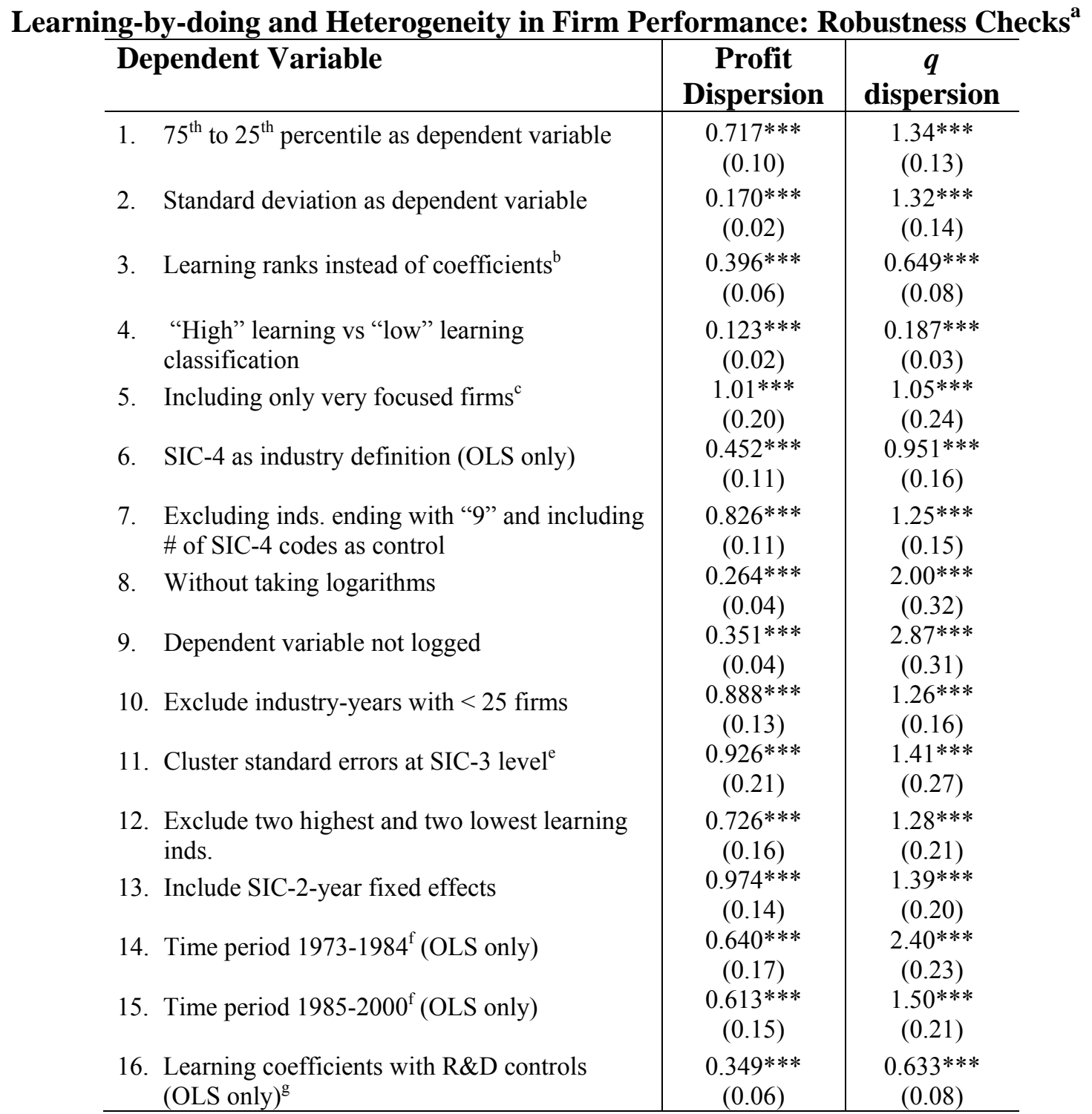

a. This table provides the results of robustness checks that use the same type of regressions as in Table 4, but with different measures of performance heterogeneity, level of aggregation, choice of time periods etc. Each line in this table is comparable to line 1 from Table 4 . Only the coefficients and standard errors on industry learning intensity are presented. Coefficients on other variables are available on request. The coefficients and standard errors have been multiplied by 100 for presentation purposes.

b. This regression includes only firms whose largest segment (by sales) accounts for at least $95 \%$ of the total sales. Due to non-availability of data before 1984, this covers the period 1984 to 2000.

c. The standard errors are computed allowing for arbitrary autocorrelation of errors within an SIC-3 industry.

d. These use learning coefficients estimated for the relevant time period as an independent variable.

e. Learning coefficients used in this regression are estimated after controlling for firm specific R\&D expenditure (the sample changes because not all firms report R\&D). 